\title{
Natural Product
} Reports

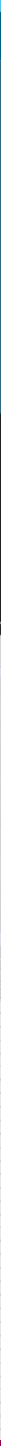

Themed issue: Metalloenzymes in Natural Product Biosynthetic Pathways - Part 2 Guest Editors: Katherine S. Ryan and Catherine L. Drennan 
Check for updates

Cite this: Nat. Prod. Rep., 2018, 35, 735

\title{
Roles of 2-oxoglutarate oxygenases and isopenicillin $\mathbf{N}$ synthase in $\boldsymbol{\beta}$-lactam biosynthesis
}

\author{
Patrick Rabe, (D) $†$ Jos J. A. G. Kamps, (ID $\dagger$ Christopher J. Schofield (D) $\dagger^{*}$ \\ and Christopher T. Lohans (D) $\dagger^{*}$
}

Covering: up to 2017

2-Oxoglutarate (2OG) dependent oxygenases and the homologous oxidase isopenicillin N synthase (IPNS) play crucial roles in the biosynthesis of $\beta$-lactam ring containing natural products. IPNS catalyses formation of the bicyclic penicillin nucleus from a tripeptide. 20G oxygenases catalyse reactions that diversify the chemistry of $\beta$-lactams formed by both IPNS and non-oxidative enzymes. Reactions catalysed by the $20 \mathrm{G}$ oxygenases of $\beta$-lactam biosynthesis not only involve their typical hydroxylation reactions, but also desaturation, epimerisation, rearrangement, and ring-forming reactions. Some of the enzymes involved in $\beta$-lactam biosynthesis exhibit remarkable substrate and product selectivities. We review the roles of 2OG oxygenases and IPNS in $\beta$-lactam biosynthesis, highlighting opportunities for application of knowledge of their roles, structures, and mechanisms.

Received 9th January 2018

DOI: $10.1039 / c 8 n p 00002 f$

rsc.li/npr

serine residues in transpeptidases (penicillin binding proteins, PBPs) that are crucially involved in bacterial cell wall biosynthesis (Fig. 2). $\beta$-Lactam resistance is substantially, but not fully, mediated by $\beta$-lactamase enzymes which catalyse hydrolysis of the $\beta$-lactam ring (Fig. 2). The new generations of natural product-derived $\beta$-lactams include cephalosporins, carbapenems, clavams, and monocyclic $\beta$-lactams. Depending on the functionalisation patterns of the core $\beta$-lactam ring system, these compounds manifest different antibacterial activity profiles and susceptibilities to the constantly evolving $\beta$-lactamases. It should be noted that naturally occurring $\beta$-lactams have roles beyond inhibiting PBPs, sometimes with important biological consequences such as for the plant toxin tabtoxin (Fig. 1). ${ }^{2-4}$

Clavulanic acid, the sole clavam to be used clinically, has relatively weak antibacterial activity, but is a potent inhibitor of some nucleophilic serine $\beta$-lactamases. Hence, like the other clinically used $\beta$-lactamase inhibitors (sulbactam, tazobactam, and avibactam; the latter being the sole non- $\beta$-lactam approved for use as a $\beta$-lactamase inhibitor), it is used in combination with a more potent antibiotic (for example, amoxicillin and clavulanic acid are combined in the drug Augmentin). ${ }^{5}$ Synthetic $\beta$-lactams have found therapeutic applications other than as antibacterials. ${ }^{6}$ Despite extensive resistance, the longevity of $\beta$-lactams as antibacterials is remarkable in the history of anti-infective medicine. ${ }^{7}$ This has led to the proposal that the combination of $\beta$-lactam inhibitors of PBPs and their PBP targets is special from a chemical perspective. ${ }^{7}$ Thus, some naturally occurring $\beta$-lactams, which likely have ancient origins

Department of Chemistry, Chemistry Research Laboratory, 12 Mansfield Road, University of Oxford, Oxford, OX1 3TA, UK. E-mail: christopher.schofield@chem.ox. ac.uk; christopher.lohans@chem.ox.ac.uk

$\dagger$ These authors contributed equally to this work. 
in bacteria, may well be highly evolved to their antibacterial roles. If this is the case it would seem likely that their biosynthesis may also be highly evolved - at least for secondary metabolites.

Whether or not $\beta$-lactams are chemically unique as antibacterials, at least from an enzymology perspective, some of the reactions occurring during $\beta$-lactam biosynthesis are spectacular (for prior relevant reviews on $\beta$-lactam biosynthesis, see ref. 4 and 8-25). Although non-oxidative reactions play crucial roles in $\beta$-lactam biosynthesis, reactions catalysed by ferrous iron and 2-oxoglutarate (2OG) dependent oxygenases and the related oxidase isopenicillin $\mathrm{N}$ synthase (IPNS) are of particular interest (Fig. 3). The $2 \mathrm{OG}$ oxygenases were first discovered during work on collagen biosynthesis and their involvement in $\beta$-lactam biosynthesis was unexpected. They typically catalyse two electron oxidations, most commonly hydroxylations, in which substrate oxidation is coupled to conversion of $2 \mathrm{OG}$ and dioxygen to succinate and carbon dioxide. ${ }^{22}$

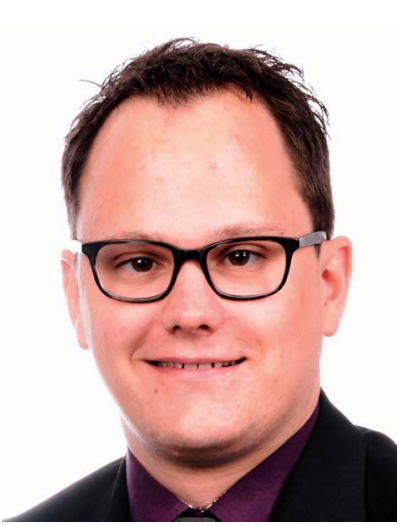

Patrick Rabe studied chemistry at the University of Braunschweig. He received the FritzWagner Award of the Helmholtz Centre for Infection Research for his master's thesis in 2013. In 2016 he finished his PhD at the Kekule-Institute of Organic Chemistry and Biochemistry at the University of Bonn on "Mechanistic Studies on Bacterial Terpene Synthases" with Prof. Jeroen S. Dickschat.

For his doctoral thesis he received the 2017 Dechema doctoral award. Since 2017 he is working in the group of Prof. Chris Schofield on mutagenesis studies and time-resolved crystallography on isopenicillin $N$ synthase with a scholarship funded by the Deutsche Akademie für Naturforscher Leopoldina.

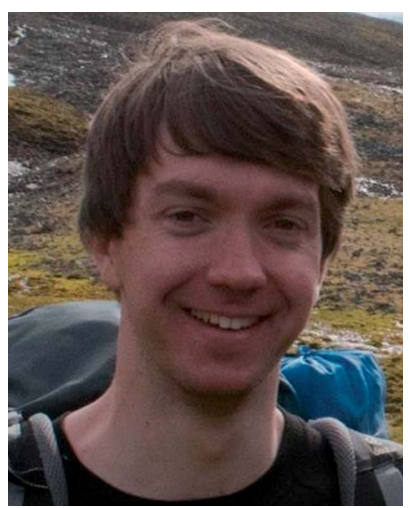

Jos Kamps obtained his bachelor's degree in chemistry from the HAN University for Applied Sciences. He finished his master's degree at the Radboud University Nijmegen in organic chemistry in 2015. During this time he worked with Dr Jasmin Mecinovic in the group of Prof. Floris Rutjes on the chemical recognition of methylated lysine in epigenetics. In 2015 he started his PhD as a student of the Synthesis for Biology and Medicine Centre for Doctoral Training with a Clarendon Award scholarship. Currently he is working in the groups of Prof. Chris Schofield and Prof. Timothy Claridge on the recognition of substrate analogues by isopenicillin $N$ synthase.
In the case of the non-penicillin $\beta$-lactam biosynthetic pathways, 2OG oxygenases play roles in diversifying the chemistry, and hence the activities, of the $\beta$-lactams formed by nonoxygen dependent chemistry. During biosynthesis of the clavam and the carbapenem bicyclic ring systems, $\beta$-lactam formation is catalysed by asparagine synthetase related enzymes (Fig. 3)., ${ }^{\mathbf{4}, 13,16,22}$ These $\beta$-lactam synthetases catalyse formation of the $\beta$-lactam ring from appropriate $\beta$-amino acid precursors, i.e. in effect they catalyse the reverse of $\beta$-lactamase catalysis (Fig. 2), but use ATP to activate the carboxylic acid. In the case of the clavams, a monocyclic $\beta$-lactam ring is formed (Fig. 3); this acts as a precursor for the formation of the bicyclic clavam ring in reactions catalysed by the $20 \mathrm{O}$ oxygenase clavaminic acid synthase (CAS). In the carbapenem pathways, $\beta$-lactam synthetases catalyse formation of the $(3 S, 5 S)$-carbapenam ring system which, at least in the pathway to carbapen-2-em-3-carboxylate, is epimerised and desaturated by CarC, a $2 \mathrm{OG}$ oxygenase, to give a $(5 R)$-carbapenem (Fig. 3). Thus, in these pathways, $2 \mathrm{OG}$

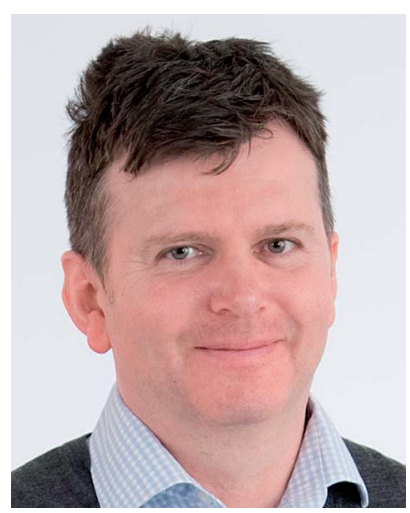

Chris Schofield is currently Head of Organic Chemistry, and a Fellow of Hertford College, University of Oxford. His current research interests include antibiotic biosynthesis and resistance, regulation of gene expression by oxygen, and epigenetics with a common theme being enzymes that catalyse chemically interesting reactions of biomedicinal importance.

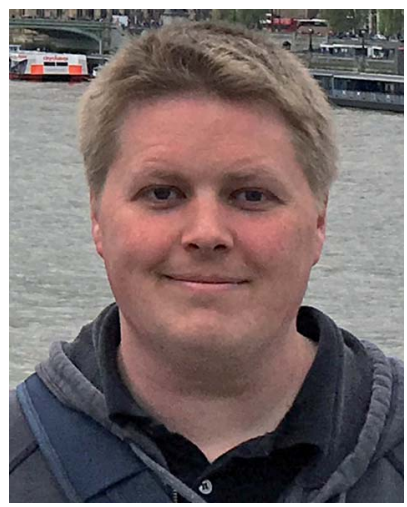

Christopher Lohans completed his PhD in 2014 in the group of Prof. John Vederas at the University of Alberta, Canada, studying the structure and biosynthesis of antimicrobial peptides. He then joined the group of Prof. Chris Schofield at the University of Oxford, UK, as a postdoctoral fellow supported by the Canadian Institutes of Health Research. His postdoctoral research has focused on investigating the mechanism and inhibition of the serine $\beta$-lactamases using NMR spectroscopy. 

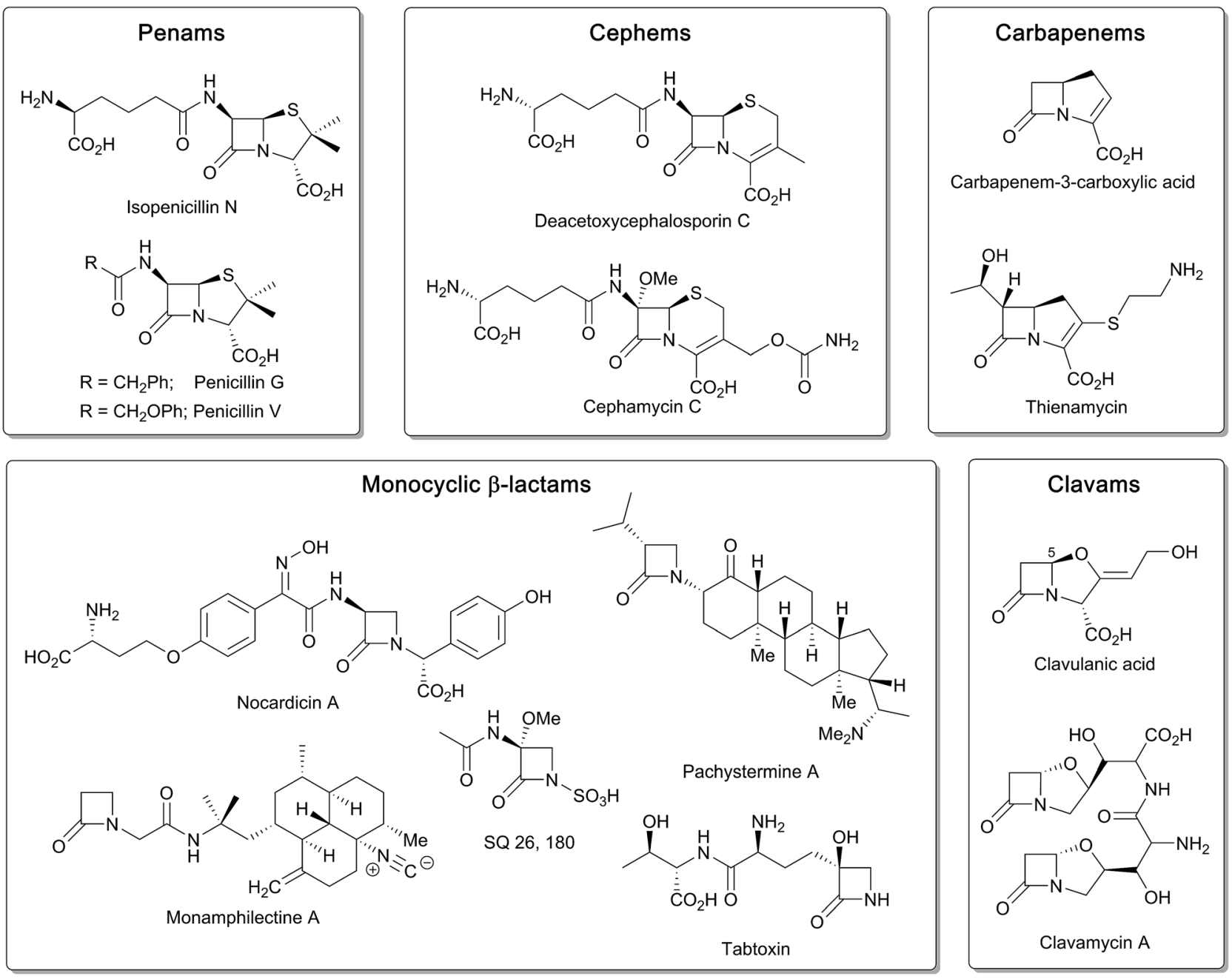

Fig. 1 Examples of the different types of naturally occurring $\beta$-lactam ring containing molecules.

oxygenases play roles both in forming a bicyclic $\beta$-lactam ring system (clavams) and in modifying a bicyclic $\beta$-lactam ring system (carbapenems) to create antibacterials., ,, $\mathbf{8 , 1 3 , 1 6 , 1 8 - 2 2}^{-12}$

Some monocyclic $\beta$-lactams, for example the nocardicins and monobactams (Fig. 3), are formed by the action of non-ribosomal peptide synthetases (NRPSs) which catalyse formation of the N1C4 $\beta$-lactam bond from an appropriate synthetase-bound precursor peptide. ${ }^{11}$ In some cases, for example the monobactams and tabtoxin, 2OG oxygenases (likely) are involved in modifications subsequent to $\beta$-lactam formation. ${ }^{4}$
Notably, both the clavam and carbapenem biosynthetic pathways involve multiple steps en route to the clinically useful bicyclic antibiotics/ $\beta$-lactamase inhibitors, for example, thienamycin and clavulanic acid (Fig. 1). Further, these pathways can result in multiple coproducts. Although it was possible to optimise clavulanic acid fermentation for commercial use, ${ }^{\mathbf{1 0}}$ this has not yet been possible in the case of clinically useful carbapenems, which are instead produced by total synthesis. ${ }^{4}$ By contrast to the, at least superficially, relatively complex carbapenem and clavam biosynthesis pathways, the pathway

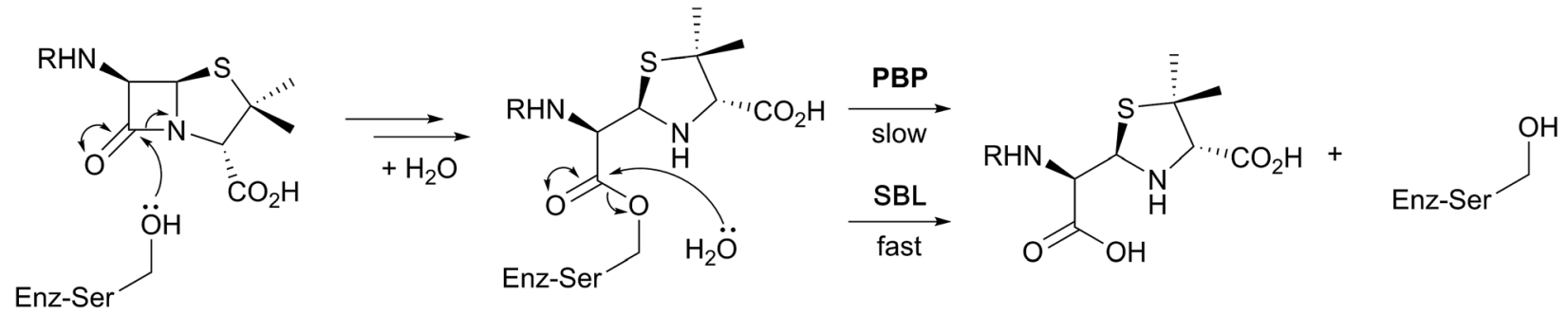

Fig. 2 Outline interaction of $\beta$-lactams (exemplified by a penicillin) with penicillin binding proteins (PBPs) and serine $\beta$-lactamases (SBLs). A major difference between the PBPs and SBLs is the stability of the acyl-enzyme complex. 
A)<smiles>CC(C)OC(C)C(C)C(NC(=O)C(CS)NC(=O)CCCC(O)C(=O)O)C(=O)O</smiles>

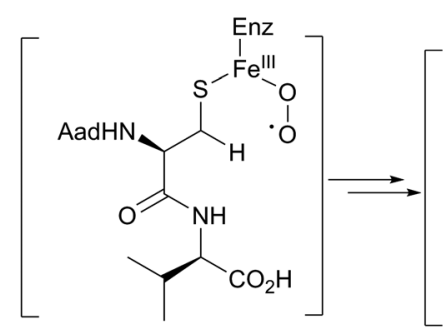

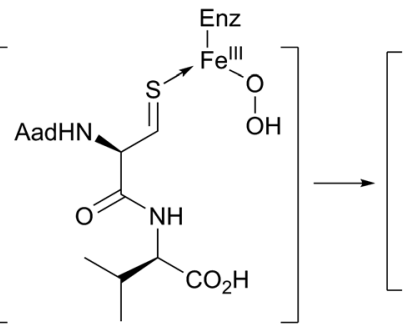

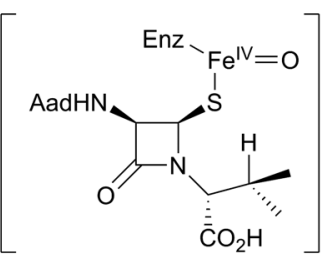

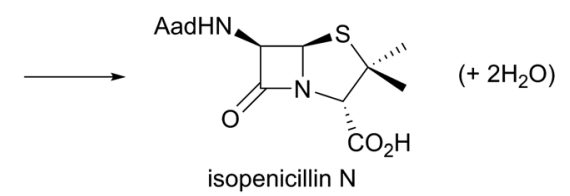

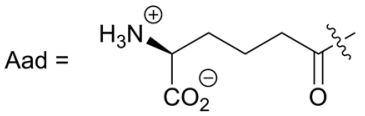

B)

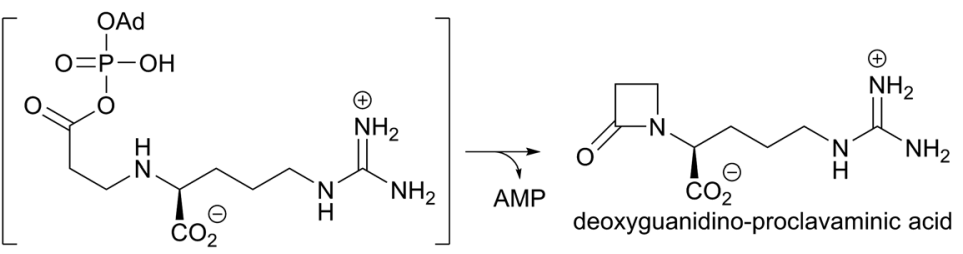

$N^{2}$-(2-carboxyethyl)arginine

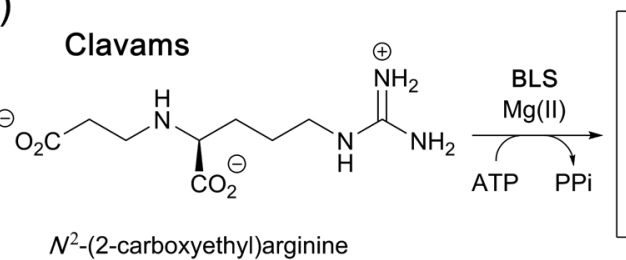

C)

\section{Carbapenems}

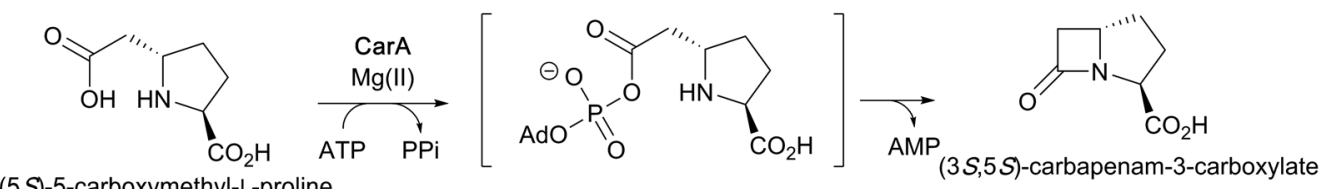
(5S)-5-carboxymethyl-L-proline

D)

Monocyclic $\beta$-lactams

Sulfazecin biosynthesis

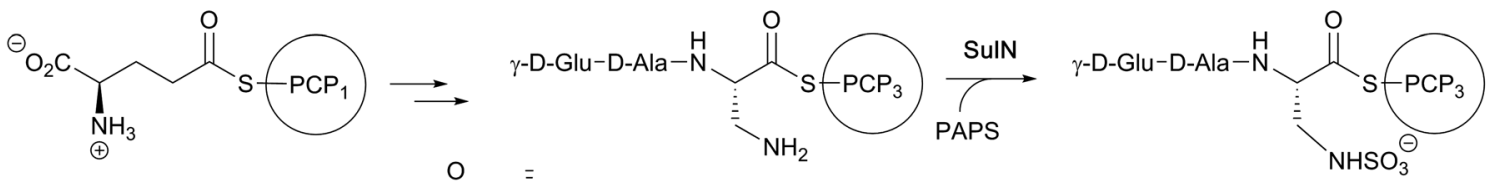

Thioester cleavage<smiles>CCCCCCCCCCCCCCCCCC(=O)O</smiles>

Nocardicin A biosynthesis

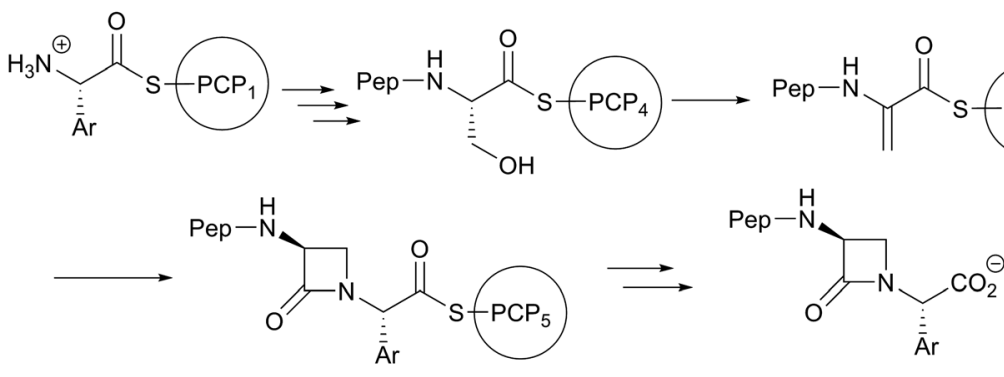

Pro-nocardicin G

Pep = L-pHPG-D-Arg-D-pHPG-

$\operatorname{Ar}=p$-hydroxyphenyl-

Fig. 3 Enzymes catalysing $\beta$-lactam formation during antibiotic biosynthesis, including: (A) isopenicillin $N$ synthase (IPNS), (B) $\beta$-lactam synthetase (BLS), (C) CarA, and (D) non-ribosomal peptide synthetases (NRPS) SuIN and NocB. Outline mechanisms/steps are shown. Note that not all cofactors, co-substrates, and products are shown. PAPS: 3'-phosphoadenosine-5'-phosphosulfate; PCP: peptidyl-carrier protein. 
leading to the penicillins and subsequently formed cephalosporins appears to be a paradigm of biosynthetic efficiency (Fig. 3).

Following pioneering work identifying the tripeptide $\delta$ - $(\mathrm{L}-\alpha-$ aminoadipoyl)-L-(cysteinyl)-D-valine (ACV) as a precursor of the penicillins, ${ }^{26,27}$ the ferrous iron dependent oxidase IPNS was isolated and shown to catalyse the four electron oxidation of ACV to form, in a single step, the bicyclic nucleus of isopenicillin N (IPN), the first formed $\beta$-lactam in the pathway. IPN is a branchpoint in some organisms; its $\delta$-( $\mathrm{L}$ - $\alpha$-aminoadipoyl)side chain can be exchanged (by the action of an amidohydrolase/acyltransferase) for a more hydrophobic side chain to give a readily extractable clinically useful penicillin, e.g. penicillins $\mathrm{G}$ or V (Fig. 1). These penicillins with hydrophobic sidechains can be used as starting points for the production of penicillins with clinically better sidechains, via enzymatically produced 6-aminopenicillanic acid (6-APA), or for the synthesis of cephalosporins, via the oxidative chemical ring expansion of the penam nucleus to that of the cephems. This chemical ring expansion of penam sulphoxides to the cephems has echoes in the biosynthetic formation of the cephalosporins (see below).

During cephalosporin biosynthesis, the side chain of IPN is epimerised to give penicillin $\mathrm{N}$, which is the substrate for deacetoxycephalosporin C synthase (DAOCS), a $20 \mathrm{G}$ oxygenase catalysing an unusual oxidative rearrangement to give deacetoxycephalosporin C (DAOC)., ${ }^{\mathbf{4 , 8 1 6 , 1 8 - 2 2}}$ Studies on the chemically interesting mechanisms and structures of IPNS and DAOCS were pioneering for the 2OG oxygenase superfamily. ${ }^{28-31}$ The procollagen prolyl hydroxylases were the first 2OG oxygenases to be identified; however, structural studies on the (animal) procollagen prolyl hydroxylases have been difficult. Unexpectedly, crystallographic studies on IPNS and 2OG oxygenases acting on small molecules ${ }^{22}$ led to the discovery that 2 OG oxygenases are very widely distributed in aerobic biology (archaea being a likely exception), including in humans where there are approximately 60 such enzymes. ${ }^{22}$ Work over the last two to three decades has shown that $2 \mathrm{OG}$ oxygenases in humans and other animals have diverse roles. In addition to collagen biosynthesis, ${ }^{32}$ these enzymes are involved in epigenetics, hypoxia sensing, chromatin regulation, DNA repair, ribosome/RNA modifications, and lipid biosynthesis. ${ }^{33-36}$ By contrast with some of their reactions in $\beta$-lactam biosynthesis, to date, the reactions assigned for $20 \mathrm{OG}$ oxygenases in animals involve chemically simple hydroxylations and $N$-methyl demethylations (also proceeding via initial hydroxylation). ${ }^{21}$

This brief review focuses on the roles of IPNS and 206 oxygenases in $\beta$-lactam biosynthesis, describing current mechanistic knowledge and highlighting opportunities for the generation of new antibiotics and for the improved production procedures for existing antibiotics.

\section{Isopenicillin $\mathrm{N}$ synthase}

The discovery of isopenicillin $\mathrm{N}$ synthase, ${ }^{27,37}$ and its marvellous reaction that enables oxidative ring closure to the densely functionalised heterocyclic penicillin ring system, illustrates the power of biosynthesis. IPNS catalyses formation of the fused $\beta$-lactam and thiazolidine core of the penicillins via the four electron oxidation of a peptide precursor with concomitant reduction of dioxygen to two water molecules. ${ }^{22,38,39}$ The IPNS substrate, i.e. the tripeptide $\delta$-(L- $\alpha$-aminoadipoyl)-L-(cysteinyl)-Dvaline (ACV) was identified more than 50 years ago. ${ }^{40} \mathrm{ACV}$ is biosynthesised by action of the non-ribosomal peptide synthetase ACV synthetase from the precursors $L-\alpha$-aminoadipic acid,

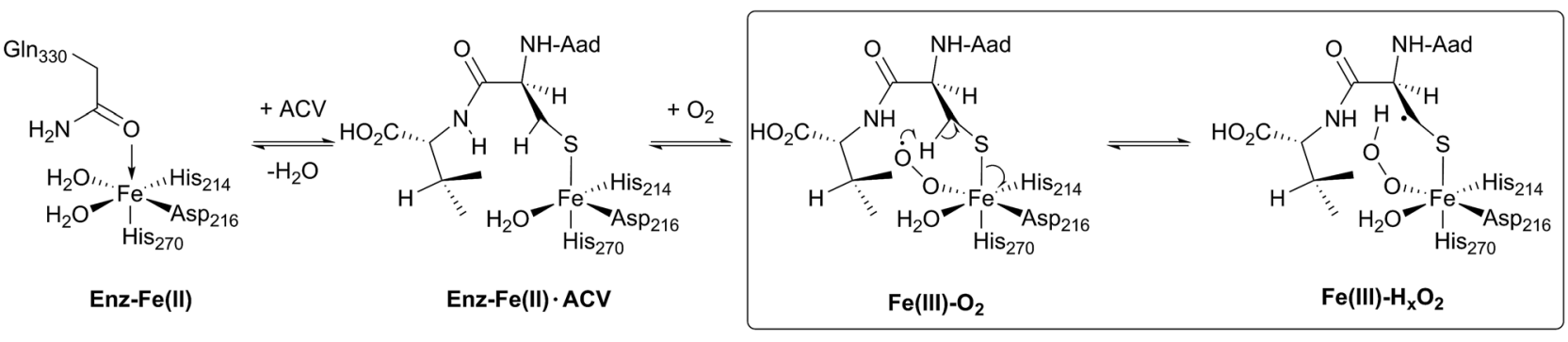

- Isopenicillin N
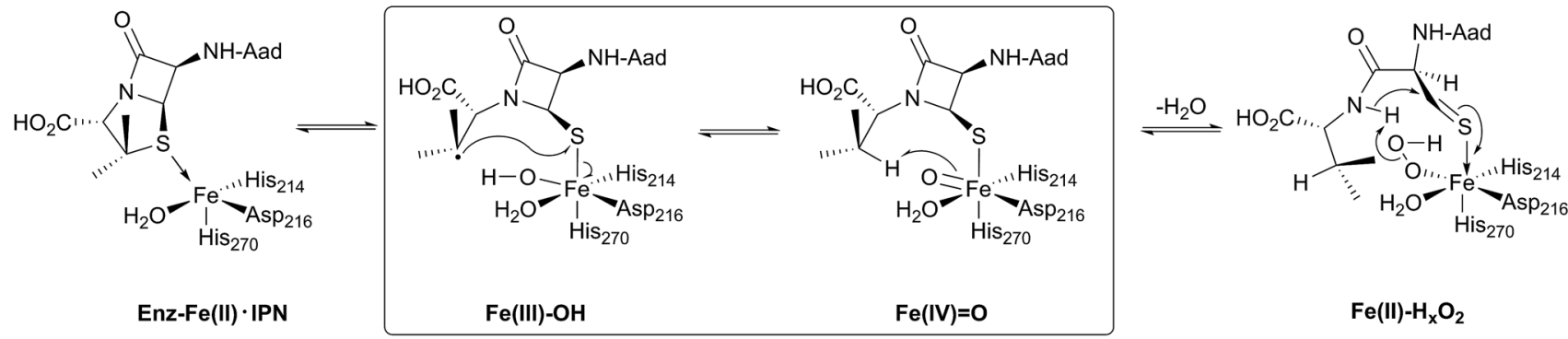

$\mathrm{Fe}(\mathrm{II})-\mathrm{H}_{\mathrm{x}} \mathrm{O}_{2}$

Fig. 4 Schematic overview of the currently proposed mechanism for isopenicillin N synthase (IPNS). Mechanism adapted from ref. 38. The highspin $\mathrm{Fe}(\mathrm{III})$-superoxo $\left[\mathrm{Fe}(\mathrm{III})-\mathrm{O}_{2}^{-}\right]$and high-spin Fe(IV)-oxo $[\mathrm{Fe}(\mathrm{IV})=\mathrm{O}]$ intermediates have been observed spectroscopically. 
L-cysteine, and L-valine, the stereochemistry of the latter being inverted during peptide formation..$^{\mathbf{4 1 - 4 3}}$

The current detailed understanding of the mechanism of IPNS is based on extensive spectroscopic, ${ }^{44-46}$ computational, ${ }^{47-50}$ crystallographic,,$^{28,29,51-58}$ and substrate analogue studies (Fig. 4). Here we summarise these results - see earlier reviews for detailed descriptions of IPNS., ${ }^{\mathbf{4 , 6 , 1 5 , 1 7 , 2 1 - 2 4 , 3 9}}$ The first crystal structure of IPNS (from Aspergillus nidulans) was obtained in complex with manganese substituting for iron; this structure revealed that in the resting enzyme state, the single active site metal is coordinated by two histidine (His214 and His270) and one aspartate residue (Asp216) as well as by the side-chain of Gln330 (Fig. 5A). ${ }^{28}$ The overall fold of IPNS is based on a distorted double-stranded $\beta$-helix (DSBH or 'jelly roll') core; this scaffold supports the triad of Fe(II) binding residues, and was subsequently shown to be conserved in 2OG oxygenases, including DAOCS. ${ }^{53,59}$ As shown in subsequent anaerobic structures obtained in the presence of ACV and Fe(II), Gln330 (ref. 28 and 60) (and one iron coordinating water) is displaced from the active site on binding of ACV, triggering
A)

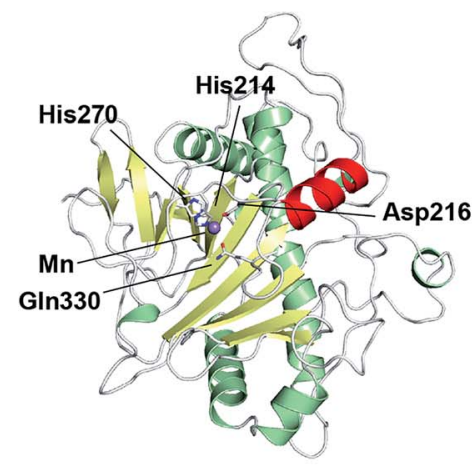

B)

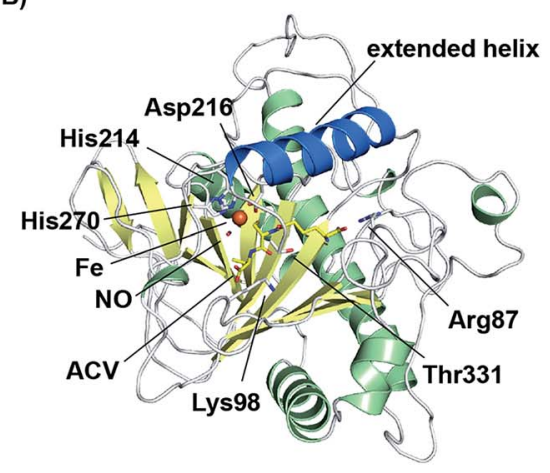

C)

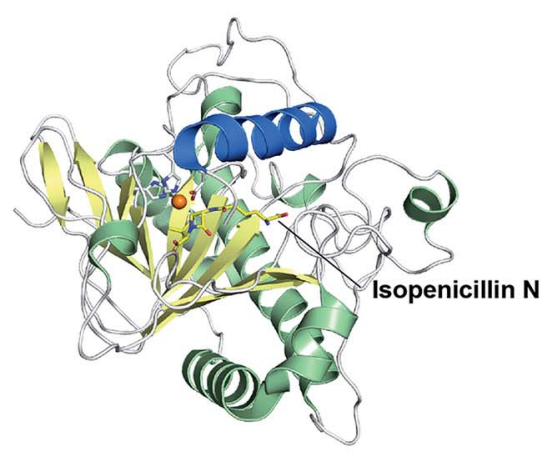

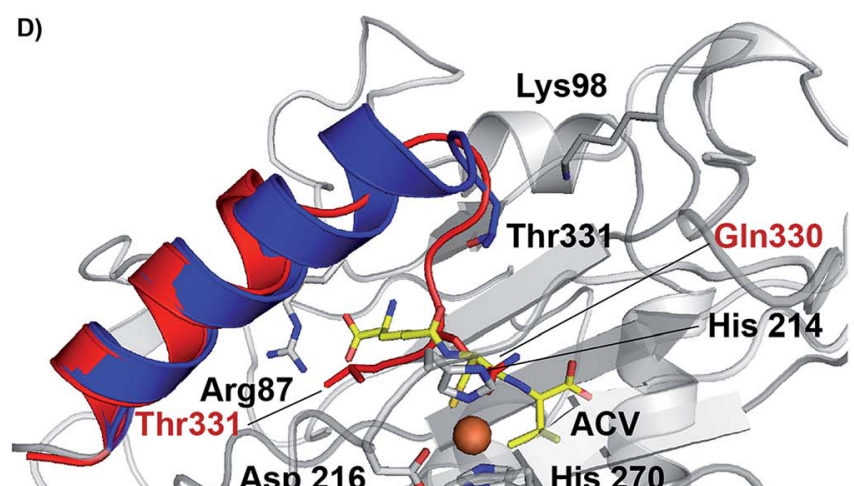

E)

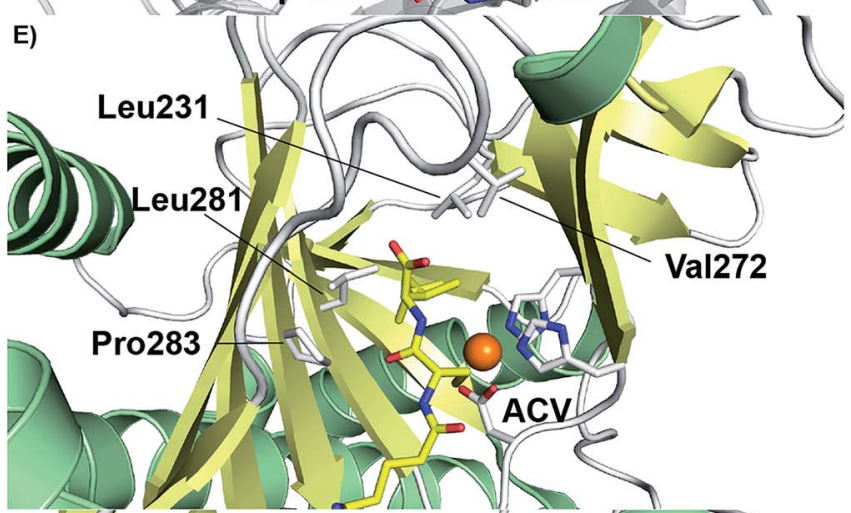

F)

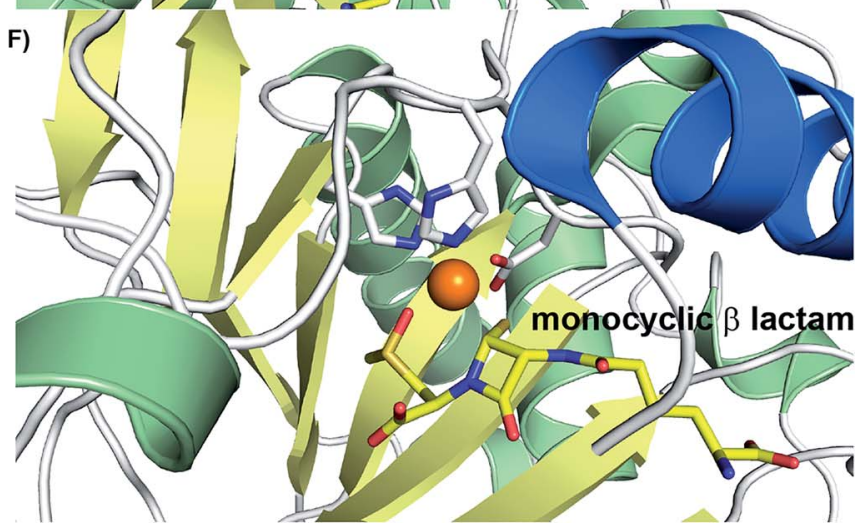

Fig. 5 Views from crystal structures of isopenicillin N synthase. (A) An IPNS-Mn complex (PDB 1IPS) ${ }^{28}$ showing coordination of metal in resting state by His214, His270, Asp216, as well as by the side-chain of Gln330 (Mn, substituting for Fe, in purple); (B) the IPNS-Fe-ACV-NO complex (PDB 1BLZ), ${ }^{29}$ showing binding of ACV by Arg87, the thiolate-Fe interaction, and enclosure of ACV at the active site, including by the extended helix; Thr331 and Lys98 form a salt bridge to constrain the conformation of the complex and to shield the active site/substrate (Fe in orange, extended helix in blue); (C) the IPNS-Fe-IPN complex (PDB 1QJE); ${ }^{55}$ (D) expanded view of the superposition of the IPNS-Fe-ACV complex active site [PDB 1BLZ; showing enclosure of ACV by the extended helix (in blue)] with the substrate-free IPNS-Mn complex (PDB 1IPS; $\alpha$-helix indicated in red); ${ }^{29}(\mathrm{E})$ hydrophobic residues bind the ACV valine isopropyl group; ${ }^{29,61}$ (F) the IPNS-Fe-monocyclic $\beta$-lactam complex (PDB $1 Q J F)^{55}$ formed after incubation with $\delta$-(L- $\alpha$-aminoadipoyl)-L-(cysteinyl)-S-methyl-D-cysteine (ACMC) and $\mathrm{O}_{2}$, supporting initial $\beta$-lactam ring formation during stepwise bicyclisation to isopenicillin $\mathrm{N}$. 
conformational rearrangement of the $C$-terminal region (Asn326-Thr331). ${ }^{29}$ Together with other conformational changes, this arrangement means that the iron-ligated ACV is enclosed at the active site (Fig. 5B). ${ }^{29,57,61}$ Conformational changes at the active site upon binding of ACV are shown in Fig. 5D. Recently reported results for a $C$-terminally truncated IPNS variant support the proposal that the $C$-terminal $\alpha$-helix shields the active site and hinders (potential) side reactions during catalysis. ${ }^{61}$

In the IPNS $\cdot \mathrm{ACV} \cdot \mathrm{Fe}(\mathrm{II})$ complex, ACV coordinates to the $\mathrm{Fe}(\mathrm{II})$ via its cysteinyl thiolate and appears conformationally constrained in a manner appropriate for $\beta$-lactam ring formation. In addition to metal complexation, ACV is bound by both hydrophobic and electrostatic interactions, the latter including the interaction of the $\mathrm{L}-\alpha$-aminoadipoyl carboxylate group with Arg-87. ${ }^{29,51,61}$ The valine isopropyl group is bound in a hydrophobic pocket formed by the side-chains of Pro283, Leu223, Leu231, Val272, and Thr221 (Fig. 5E). Recent mutational studies on the role of these residues highlights their importance in substrate recognition and catalysis. ${ }^{\mathbf{6 1}}$

Crystallographic analysis of the IPNS·ACV $\cdot \mathrm{Fe}(\mathrm{II}) \cdot \mathrm{NO}$ complex $^{29}$ showed that NO (acting as a dioxygen analogue) binds adjacent to the cysteinyl thiol with the oxygen atom of the complexed NO directed toward the cysteinyl $\beta$-carbon. These observations support formation of the $\beta$-lactam ring prior to the thiazolidine ring (Fig. 5B) and are consistent with prior kinetic studies, in particular those employing deuterium labelled ACV substrates (with $\left[3,3-{ }^{2} \mathrm{H}_{2}\right]$-Cys or $\left[3-{ }^{2} \mathrm{H}_{1}\right]$-Val labelled ACV
A)<smiles>CC(C)N[C@H](C(=O)N[C@H](C(=O)O)C(C)C)C(F)(F)CS</smiles><smiles>[R]CC(C)C(OC(=O)[C@@H](NCCC)C([R])S)C(C)C[R]</smiles>
$\mathrm{R}=\mathrm{CH}_{3}, \mathrm{R}_{1}=\mathrm{H}$<smiles>CC(C)N[C@@H](CS)C(=O)N[C@@H](CSC[C@H](C)OC(C)C)C(=O)O</smiles><smiles>CCCCN[C@@H](C(=O)N[C@@H](C(=O)O)C(C)C)C(F)(F)C(=O)O</smiles><smiles>[R]CC(C)C(OC(=O)[C@@H](NC(C)C[R]#[R])C([R])S)C(=O)O</smiles><smiles>CCCCCCC(NC(=O)[C@@H](CS)NC(=O)O)C(=O)O</smiles>

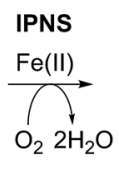<smiles>CCCCN[C@H](C(=O)OC(C(=O)O)C(C)C)[C@H](C)S</smiles>

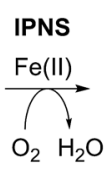

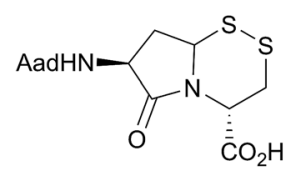<smiles>C=C(S)[C@H](NCCCCCC)C(=O)OC(C(=O)O)C(C)CO</smiles>

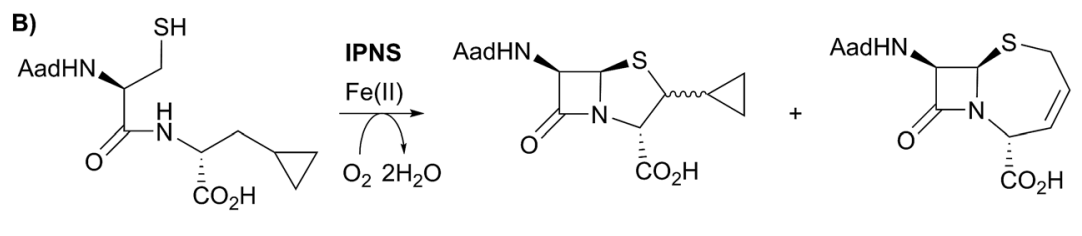

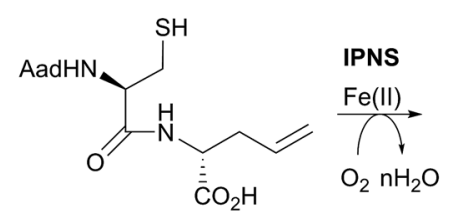

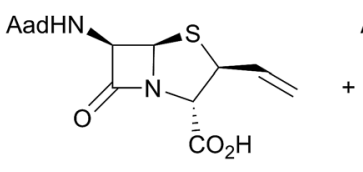<smiles>C=C[C@H]1S[C@@H]2[C@@H](NCCCC)C(=O)N2[C@H]1C(=O)O</smiles><smiles>CCCCN[C@H]1C(=O)N2[C@@H](C(=O)O)C=CCS[C@H]12</smiles><smiles>CCCCN[C@H]1C(=O)N2[C@@H](C(=O)O)C[C@@H](O)CS[C@H]12</smiles><smiles>CCCCN[C@H]1C(=O)N2[C@@H](C(=O)O)C[C@@H](O)CS[C@H]12</smiles><smiles>CCCCN[C@H]1C(=O)N2[C@@H]1SC[C@@H](CO)[C@@H]2C(=O)O</smiles>

Fig. 6 (A) Substrate analogues exemplifying the catalytic promiscuity of IPNS with respect to the type of oxidation reaction catalysed. The products derived from the depsipeptide analogues and the $S$-methyl cysteine analogue were observed crystallographically. (B) Examples showing the ability of IPNS to make different $\beta$-lactam ring systems by substituting the $C$-terminal valine of the natural ( $\delta$ - $(L-\alpha$-aminoadipoyl)- $L$ (cysteinyl)-D-valine) substrate. 
residues). ${ }^{22,57}$ Further support for initial $\beta$-lactam ring formation came from crystallographic analyses of IPNS with the substrate analogue $\delta$-(L- $\alpha$-aminoadipoyl)-L-(cysteinyl)- $S$-methylD-cysteine (ACMC), which was crystallised under anaerobic conditions, then exposed to a high pressure of oxygen. The resultant structure showed formation of a monocyclic $\beta$-lactam (with oxidation of the $S$-methyl group), ${ }^{55,56}$ providing strong experimental support for initial $\beta$-lactam formation (Fig. $5 \mathrm{~F}$ and 6A).

Mechanistic proposals for IPNS arising from early kinetics, substrate analogue, and crystallographic studies are supported by recent stopped flow, modelling, and spectroscopic (including by Mossbauer) studies. ${ }^{38}$ Following ACV binding/ligation to the active site $\mathrm{Fe}$ (II) (involving displacement of one metal ligated water and incompletely defined induced fit processes), dioxygen binds and reacts to form an (unusually stable) iron(III) superoxo species. ${ }^{38}$ The first step in the ACV-catalysed reaction involves abstraction of the pro- $(S)$ cysteinyl C-3 hydrogen to give a thioalkyl radical. After inner-sphere electron transfer, a ferrous hydroperoxo intermediate $[\mathrm{Fe}(\mathrm{II})-\mathrm{OOH}]$ and a thioaldehyde are formed. Heterolysis of the peroxo bond to form a water molecule, concomitant with abstraction of the cysteinyl-valine amido hydrogen by the terminal peroxide oxygen, and nucleophilic attack of the amide nitrogen onto the thioaldehyde forms a monocyclic $\beta$-lactam intermediate linked to a ferryl species $[\mathrm{Fe}(\mathrm{Iv})=\mathrm{O}]$ (Fig. 4). ${ }^{55,57}$ This second key intermediate, which has been characterised by spectroscopy, ${ }^{38}$ mediates radical type abstraction of the ACV valine C-3 hydrogen resulting in a ferric hydroxyl [Fe(III)-OH] species. Reaction of the valinyl radical on the sulphur enables isopenicillin $\mathrm{N}$ product formation and restoration of the metal to the $\mathrm{Fe}(\mathrm{II})$ state (Fig. 4 and $5 \mathrm{C}$ ). ${ }^{55}$

A feature of IPNS is its ability to accept substrate analogues, with a few selected examples shown in Fig. 6., 15,22,62-78 The substrate analogue work has provided further insight into the mechanism of IPNS, and highlights the potential of non-heme oxygenases for production of synthetically challenging molecules. In terms of biocatalysis, the observation that ACV analogues lacking the amino group in the $\delta$-(L- $\alpha$-aminoadipoyl)side chain are IPNS substrates has potential utility in pathway engineering., ${ }^{\mathbf{4} 15}$ Some ACV analogues with hydrophobic groups substituting for the $\delta$-(L- $\alpha$-aminoadipoyl) residue of ACV are IPNS substrates, raising the possibility of engineering both ACV synthetase and IPNS to produce clinically useful penicillins in two enzyme catalysed steps., ${ }^{\mathbf{4 1 5}}$

One mechanistic insight arising from the substrate analogue work is the delicate nature of the balance in regiochemistry of IPNS catalysed peptide oxidations. By way of example, $\delta-(L-\alpha-$ aminoadipoyl)-L-(3,3-difluorohomocysteinyl)-D-valine is oxidised by IPNS giving neither bicyclic nor monocyclic products; instead the 3,3-difluorohomocysteinyl residue undergoes four electron oxidation resulting in a thiocarboxylic acid (Fig. 6A). ${ }^{62}$ Use of $\delta$-(L- $\alpha$-aminoadipoyl)-L-(homocysteinyl)-Dcysteine enabled trapping of a bicyclic $\gamma$-lactam as a disulfide (Fig. 6A) ${ }^{63,78}$ More recent work in the crystalline state has employed substrate analogues in which the cysteinyl-valine amide of ACV is replaced with an ester (i.e., depsipeptide analogues), with particularly interesting results being obtained with $\beta$-methyl cysteinyl analogues; the depsipeptide with a cysteinyl (3S)-methyl group yielded a thioenol/thioketone, whereas one depsipeptide without the methyl group yielded a thiocarboxylic acid. ${ }^{\mathbf{6 8 , 6 9}}$

ACV analogues employing valine substitutes strikingly reveal the potential for promiscuity in the reactions of the monocyclic $\beta$-lactam ferryl intermediate, at least with unnatural substrates (Fig. 6). ${ }^{4,15}$ Multiple products have been isolated with some unsaturated or cyclopropane ring containing valine analogues, with the balance between products being manipulated by use of deuterium labels. ${ }^{15,22,63-66}$ This promiscuity, including the ability to form 'expanded' ring products, is clearly manifested with replacement of the D-valine of ACV by D-allylglycine or by D-cyclopropylalanine (Fig. 6B). At least some of the observed products are formed via radical intermediates. ${ }^{63-66}$

\section{2OG oxygenases in cephalosporin biosynthesis - deacetoxycephalosporin C and deacetylcephalosporin C synthase}

The committed step in cephalosporin biosynthesis is catalysed by deacetoxycephalosporin $\mathrm{C}$ synthase (DAOCS). ${ }^{4}$ Eukaryotic microorganisms have a single bifunctional 2OG oxygenase DAOCS/DACS ${ }^{79}$ which has both deacetoxycephalosporin C synthase (DAOCS) and deacetylcephalosporin $\mathrm{C}$ synthase (DACS) activities. By contrast, in prokaryotes two distinct enzymes are highly, but incompletely, selective for the penam expansion (DAOCS) ${ }^{80}$ and the DAOC hydroxylation steps (DACS). ${ }^{81-83}$ Isopenicillin $\mathrm{N}$ is not a substrate for DAOCS, though note that $\delta$-(D- $\alpha$-aminoadipoyl)-L-(cysteinyl)-D-valine is an IPNS substrate. ${ }^{\mathbf{4 , 8 4 , 8 5}}$ In microorganisms producing cephalosporins, the $\delta$-(L- $\alpha$-aminoadipoyl) side chain of isopenicillin $\mathrm{N}$ undergoes epimerisation to give the $\delta$-(D- $\alpha$-aminoadipoyl) side chain of penicillin $\mathrm{N}$, which is the DAOCS substrate. In prokaryotes, this reaction is catalysed by a pyridoxal dependent epimerase. ${ }^{\mathbf{8 6 - 9 0}} \mathrm{In}$ eukaryotes, a different epimerisation system is present, encoded for by genes cefD1 and cefD2; the encoded protein CefD1 is proposed to catalyse CoA ester formation, while CefD2 is proposed to catalyse epimerisation..$^{\mathbf{9 1 , 9 2}}$

At least one $20 \mathrm{OG}$ oxygenase is also involved in the $7 \alpha$-functionalisation of cephalosporins. Two types of $7 \alpha$-functionalised cephalosporins with potent antibiotic activity are known: the cephamycins with a $7 \alpha$-methoxy group, and the cephabacins with a $7 \alpha$-formylamino group. Whilst the biosynthesis of the latter has not been defined, the methyl group and the oxygen of the $7 \alpha$-methoxy group are derived from methionine and dioxygen, respectively. ${ }^{93}$ Studies with cell-free extracts of Streptomyces clavuligerus, using $O$-carbamoyl DAC as a substrate, showed the process is dependent on Fe(II), 2OG, and $S$-adenosylmethionine. Evidence for sequential hydroxylation then methylation came from the isolation of the $7 \alpha$-hydroxy- $O$-carbamoyl DAC. Sequencing of the cephamycin biosynthesis gene cluster suggests cmcI and $\mathrm{cmcJ}$ encode for a methyltransferase and a $7 \alpha$-hydroxylase, respectively. ${ }^{94}$ The assignment of $\mathrm{CmcI}$ as a methyltransferase was supported by structural studies; ${ }^{95}$ as yet 
no biochemical studies on recombinant $\mathrm{CmcJ}$ have been reported. The improvement of $7 \alpha$-methoxycephalosporins production by overexpression of $\mathrm{cmcJ}$ and $\mathrm{cmcI}$ in $S$. clavuligerus has been recently reported. ${ }^{96}$

Insight into the DAOCS/DACS mechanisms has come from isotopic labelling experiments, spectroscopy, and crystallog-

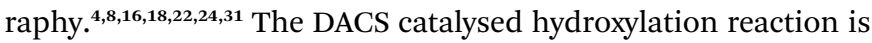
typical of 2OG-dependent oxygenase type reactions, albeit occurring at an allylic position (Fig. 7B); it likely proceeds via hydrogen abstraction involving a ferryl intermediate, generated by reaction of $2 \mathrm{OG}$ and dioxygen with consequent production of carbon dioxide and succinate, as proposed for other $20 \mathrm{OG}$ oxygenases. ${ }^{\mathbf{4}, \mathbf{8} 22}$ Consistent with this, the reaction proceeds with, at least, partial retention of stereochemistry. ${ }^{97}$ By contrast, the DAOCS catalysed oxidative ring expansion reaction (Fig. 7A) is unique to date in enzymology. It does, however, have precedent in the non-enzymatic oxidative rearrangement of penicillins to cephalosporins, in which a penicillin $\beta$-sulfoxide is converted into a cephalosporin where the (pro- $S$ ) $\beta$-methyl group of a penicillin is incorporated into the dihydrothiazine ring. ${ }^{98}$ Studies in cells and with isolated enzyme have shown that the $\beta$-methyl group of penicillin $\mathrm{N}$ forms the endocyclic $\mathrm{C}-3$ carbon of DAOC (Fig. 7).$^{98-100}$ By contrast with the results for the DACS reaction, cellular studies employing (3-pro- $R$ )-valine, with a ${ }^{1} \mathrm{H} /{ }^{2} \mathrm{H} /{ }^{3} \mathrm{H}$ labelled chiral methyl group at the position that forms the endocyclic C-3 of cephalosporin $\mathrm{C}$, imply loss of stereochemistry during the DAOCS reaction (Fig. 7A), suggesting the involvement of a radical intermediate, as supported by biomimetic studies. ${ }^{\text {101-103 }}$

Work with deuterium labelled penicillin $\mathrm{N}$ has shown that during the DAOCS reaction, a hydrogen is removed from the (pro- $S$ ) $\beta$-methyl group prior to loss of the C-3 hydrogen. ${ }^{\mathbf{1 0 4 , 1 0 5}}$ Further, incubation with $\left(3{ }^{2} \mathrm{H}\right)$ penicillin $\mathrm{N}$ resulted in a substantial increase in the observed amount of $3 \beta$-hydroxy- $3 \alpha$ -

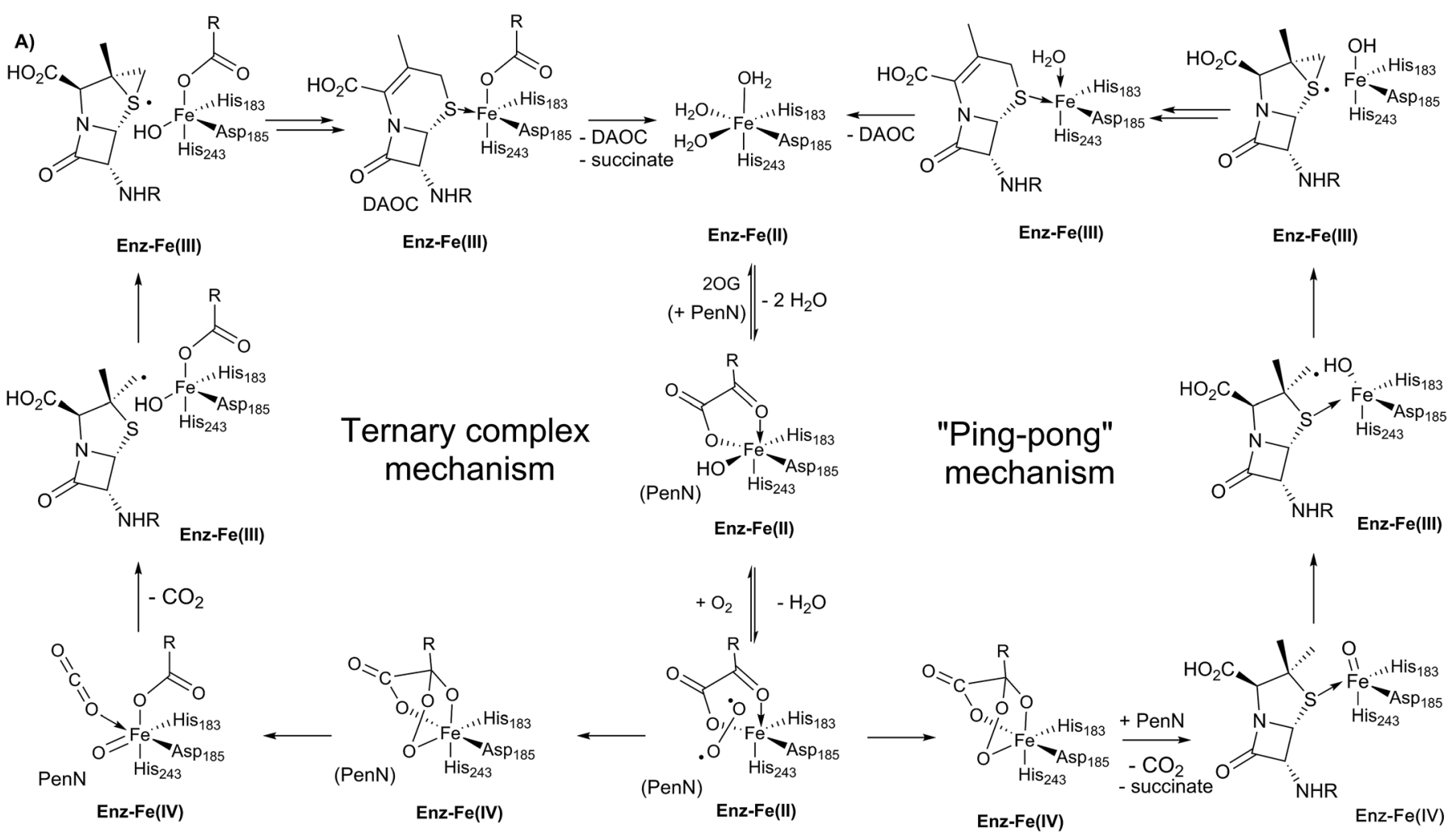<smiles>[R]N[C@H]1C(=O)N2C(C(=O)O)=C(CO)CS[C@H]12</smiles>

C)<smiles>C[C@@]1(O)CS[C@@H]2[C@H](NC(=O)O)C(=O)N2[C@H]1C(=O)O</smiles>

Fig. 7 Schematic overview of proposed mechanisms for deacetoxycephalosporin C synthase (DAOCS). (A) The ternary complex mechanism shown employs the consensus process for formation of the ferryl intermediate in the presence of the substrate (penicillin $\mathrm{N}$ ) as supported by stopped-flow kinetic assays and binding studies by non-denaturing mass spectrometry and NMR. ${ }^{106}$ An alternative "ping-pong" mechanism has been proposed based on crystallographic information - see text. Note that penicillin $N(P e n N)$ binds to the enzyme-Fe(II)-2OG complex in the case of the ternary complex mechanism. (B) The allylic oxidation of deacetoxycephalosporin C (DAOC) to give deacetylcephalosporin C (DAC) as catalysed by deacetylcephalosporin C synthase (DACS). (C) Structure of the byproduct observed in DAOCS catalysis. 
methylcepham (Fig. 7C), which is only otherwise observed as a minor by-product. ${ }^{\mathbf{1 0 4 , 1 0 5}}$ Coupled with studies on other $2 \mathrm{OG}$ oxygenases, these and other kinetic observations led to a proposal for DAOCS catalysis in which $2 \mathrm{OG}$ binding is followed by that of penicillin N. Recent spectroscopic studies support this mechanism and the formation of a ternary DAOCS $2 \mathrm{OG} \cdot$ penicillin $\mathrm{N}$ complex. ${ }^{\mathbf{1 0 6}}$ Following binding of dioxygen, oxidative decarboxylation of $2 \mathrm{OG}$ can occur to form carbon dioxide, succinate, and a ferryl intermediate as proposed in DACS catalysis. The ferryl intermediate can abstract a hydrogen to give a $\beta$-methyl radical which ring expands to give a cepham radical, which then loses a hydrogen atom to give DAOC (i.e., the ternary complex mechanism in Fig. 7A). Deuteration at the penicillin N C-3 position favours hydroxylation to give $3 \beta$-hydroxy- $3 \alpha$-methylcepham (Fig. $7 \mathrm{C}$ ), due to operation of a primary isotope effect. ${ }^{104}$

In 1998, an X-ray crystal structure of DAOCS from S. clavuligerus, the first of a $20 \mathrm{OG}$ oxygenase, was reported. ${ }^{30}$ The structure revealed the distorted double-stranded $\beta$-helix also present in IPNS $^{28,29}$ and other 2 OG oxygenases. ${ }^{\mathbf{4 , 8 2 2 , 1 0 7}}$ As for IPNS, ${ }^{28,29}$ DAOCS (and by implication the other $20 \mathrm{O}$ oxygenases involved in cephalosporin biosynthesis) has the conserved $\mathrm{Fe}$ (II) binding triad 2-His-1-Asp motif (His183, Asp185, and His243 in DAOCS). Structures were obtained for DAOCS $\cdot \mathrm{Fe}(\mathrm{II}) \cdot 2 \mathrm{OG}$ and DAOCS $\cdot \mathrm{Fe}(\mathrm{II}) \cdot$ succinate complexes. These are consistent with operation of the consensus ordered sequential mechanism for 2OG oxygenases, ${ }^{107-111}$ in which $2 \mathrm{OG}$ binds prior to penicillin $\mathrm{N}$, and the DAOC product leaves prior to succinate (Fig. 8A and B). $2 \mathrm{OG}$ was observed to bind in a bidentate manner to the active site metal via its oxalate group with displacement of two water molecules. ${ }^{30}$ A second critical interaction for $20 \mathrm{O}$ binding is via its 5-carboxylate with Arg258 which is part of a conserved RXS $2 \mathrm{OG}$ binding motif present in DAOCS subfamily $20 \mathrm{O}$ oxygenases (including biomedicinally important human enzymes) ${ }^{22}$ (Fig. 8A). Mutagenesis of Arg258 (to Gln258) severely reduces DAOCS activity. ${ }^{112}$

Although it is predominantly monomeric in solution, DAOCS was initially crystallised as a trimer in which the $C$ terminus of one protein monomer inserts into the active site of its neighbour monomer; ${ }^{30}$ this crystal form is likely not amenable to obtaining substrate complexes. Mutagenesis/truncation of the $C$-terminus yielded a catalytically active form of DAOCS which crystallises as a monomer. ${ }^{\mathbf{1 1 3 1 1 4}}$ Structures were obtained of complexes with the (poor) substrate analogue penicillin $\mathrm{G}$ and ampicillin as well as one with the product DAOC (Fig. 8C). ${ }^{\mathbf{1 1 4}}$ Structures of DAOCS-Fe(II) - penicillin G $\cdot 2 \mathrm{OG}$ and DAOCS $\cdot \mathrm{Fe}(\mathrm{II}) \cdot$ ampicillin $\cdot 2 \mathrm{OG}$ revealed apparent overlapping of the penicillin substrate analogue with the co-substrate (2OG) binding sites. These results were interpreted as supporting an unprecedented "ping-pong" mechanism in which $20 \mathrm{OG}$ and dioxygen react to give a ferryl intermediate, succinate leaves, and only then does penicillin $\mathrm{N}$ bind with subsequent ring expansion as proposed above (Fig. 7A). ${ }^{114}$ However, more recent studies on DAOCS presteady-state kinetics and binding studies with different substrate analogues ${ }^{\mathbf{1 0 6}}$ do not support such a mechanism, instead suggesting that the formation of a ternary DAOCS $\cdot \mathrm{Fe}(\mathrm{II}) \cdot 2 \mathrm{OG} \cdot$ penicillin substrate complex occurs after
A)

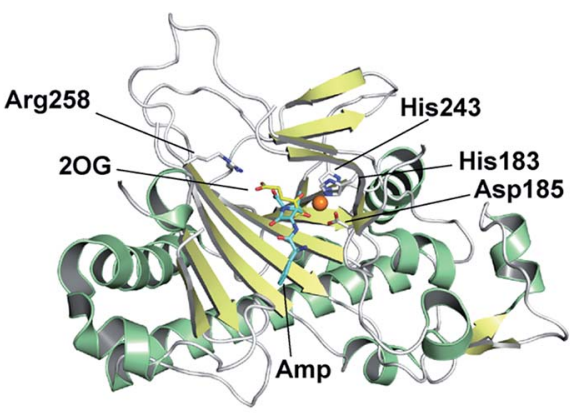

B)

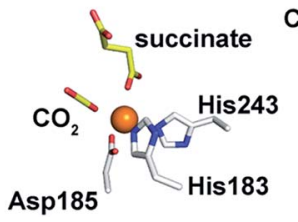

C)

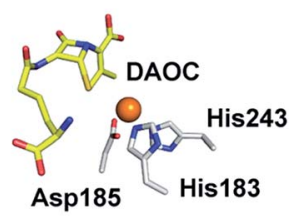

Fig. 8 Structural views for deacetoxycephalosporin $C$ synthase (DAOCS). (A) The overall fold (PDB 1UNB) ${ }^{114}$ and selected active site elements of DAOCS (including the Fe binding residues) are conserved with IPNS. (B) Active site view from a DAOCS-Fe-succinate- $\mathrm{CO}_{2}$ complex structure (DAOCS R307A mutant, PDB 1E5H): ${ }^{114}$ note the similar arrangement of Fe-binding ligands to that in IPNS (Fig. 5); (C) active site view from a DAOCS-Fe-DAOC product structure (PDB 1W2O): 114 note the apparent overlap of the DAOC and 2OG/succinate binding sites - with other structures this led to the proposal of an unusual mechanism for DAOCS - see text and Fig. 7.

2 OG binding. Future studies on DAOCS could focus on characterising details of the proposed radical mechanism of ring expansion.

The polar $\delta$-(D- $\alpha$-aminoadipoyl)-side chain of naturally occurring cephalosporins is not clinically useful and makes them difficult to extract. In order to enable production of cephalosporins with hydrophobic (or, potentially clinically useful side-chains) which are easier to purify, approaches guided by structural studies or directed evolution to engineer the natural cephalosporin biosynthesis pathway are being employed. ${ }^{112,115-131}$ One approach involves using mutagenesis to alter the selectivity of DAOCS such that it efficiently accepts penicillins with hydrophobic side-chain (e.g. penicillin $\mathrm{G}$ ) rather than the natural $\delta$-(D- $\alpha$-aminoadipoyl) side chain. The main focus of recent studies has been on modifications in the $C$ terminal region of DAOCS, which is involved in substrate recognition. ${ }^{\mathbf{1 1 8 , 1 2 3 , 1 3 1}}$

\section{The role of clavaminic acid synthase (CAS) in clavam biosynthesis}

The biosynthetic pathways leading to clavams contrast with those for the penicillins and cephalosporins, both with respect to $\beta$-lactam ring formation and functionalisation processes. The initial steps of clavam biosynthesis are believed to occur via a conserved pathway leading to $(3 S, 5 S)$-clavaminic acid, which acts as a branchpoint for diverging pathways yielding $(3 R, 5 R)$ clavulanic acid and the $(5 S)$-clavams. ${ }^{\mathbf{1 3 2}}$ The formation of clavaminic acid involves the remarkable $20 \mathrm{O}$ oxygenase clavaminic 
acid synthase (CAS), which catalyses three distinct oxidations, i.e., hydroxylation, cyclisation, and desaturation reactions.

The committed step in clavam biosynthesis comprises reaction of L-arginine with glyceraldehyde-3-phosphate, yielding the $\beta$-amino acid $N^{2}$-(2-carboxyethyl)arginine (CEA), as catalysed by the thiamine pyrophosphate enzyme, carboxyethylarginine synthase (CEAS). The $(3 S, 5 S) \beta$-lactam core of the clavams is next formed via an ATP-dependent reaction catalysed by a $\beta$-lactam synthetase (BLS). CAS then catalyses the hydroxylation of deoxyguanidino-proclavaminic acid, yielding guanidino-proclavaminic acid, in a reaction typical of $20 \mathrm{O}$ oxygenases. ${ }^{133}$ Prior to further oxidation by CAS, proclavaminate amidino hydrolase (PAH) catalyses hydrolysis of the guanidino group of guanidino-proclavaminic acid, forming proclavaminic acid. ${ }^{\mathbf{1 3 4 - 1 3 6}}$ CAS then catalyses two further reactions: first the unusual bicyclisation of proclavaminic acid to form dihydroclavaminic acid, then a desaturation reaction to form clavaminic acid. ${ }^{137}$ The subsequent steps leading to clavulanic acid, in which the amino group of $(3 S, 5 S)$-clavaminic acid is replaced with a hydroxyl group and the two stereocenters are epimerised, have not been fully elucidated. ${ }^{\mathbf{1 3 8}}$ The final step in the pathway involves NADPH/NADH dependent reduction of $(3 R, 5 R)$-clavaldehyde to give clavulanic acid..$^{139-141}$ Another oxygenase, potentially a P450 type enzyme, may be involved in the installation of the allylic hydroxyl oxygen of clavulanic acid, as growth of the producing organism in an ${ }^{18} \mathrm{O}_{2}$ atmosphere resulted in isotopic labeling at this position. ${ }^{\mathbf{1 4 2}}$
Whilst investigating the cell-free production of clavulanic acid, Elson et al. discovered the production of clavaminic acid and proclavaminic acid by a clavulanate-producing strain of $S$. clavuligerus. ${ }^{134}$ They also described the isolation of native CAS from this strain, which catalysed the conversion of proclavaminic acid into clavaminic acid (Fig. 9). CAS was shown to be a $2 \mathrm{OG}$ oxygenase, with conversion of proclavaminic acid into clavaminic acid requiring two equivalents of $2 \mathrm{OG}$. Incubation of ${ }^{13} \mathrm{C}$-labeled proclavaminic acid or clavaminic acid with the clavulanic acid producer resulted in isotopic incorporation into clavulanic acid, indicating their roles as intermediates in clavulanic acid biosynthesis. ${ }^{\mathbf{1 4 3}}$

While monitoring the conversion of proclavaminic acid into clavaminic acid by CAS, the presence of a minor species was observed by ${ }^{1} \mathrm{H}$ NMR; ${ }^{135}$ incubation of CAS with C-3 deuteriumlabeled proclavaminic acid resulted in accumulation of this species, apparently due to a primary isotope effect, allowing for its isolation and characterisation as dihydroclavaminic acid (Fig. 9). This indicated that the cyclisation reaction catalysed by CAS, wherein the oxazolidine ring is formed, precedes the CAScatalysed desaturation reaction. It was subsequently demonstrated that CAS catalyses the efficient hydroxylation of deoxyguanidino-proclavaminic acid to give guanidinoproclavaminic acid, ${ }^{133}$ which is the substrate for PAH. Studies employing an affinity label targeting CAS implied that all three reactions were catalysed by a single active site and required only a single iron center. ${ }^{141,142}$ Although the ability of a single active<smiles>N=C(N)NCCC[C@H](N)C(=O)O</smiles>
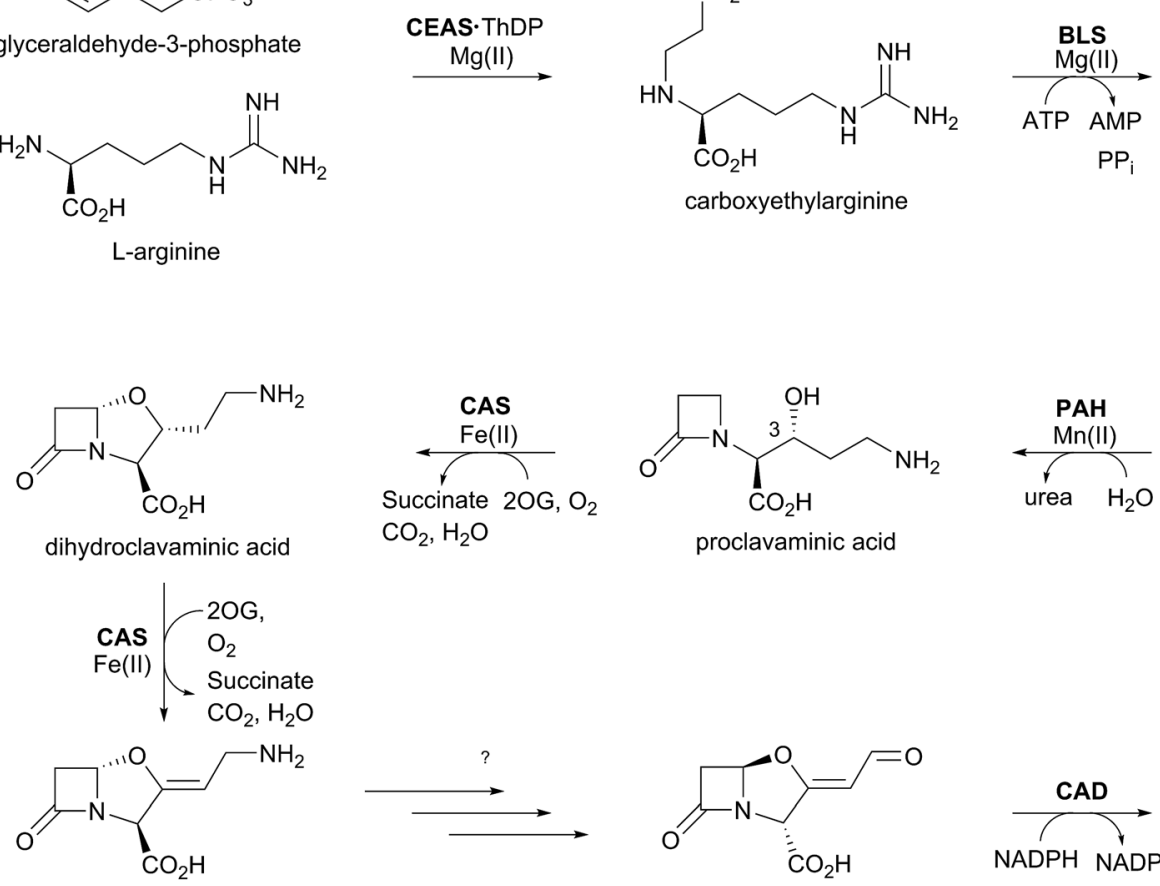

clavaminic acid<smiles>N=C(N)NCCCC(NCCC(=O)O)C(=O)O</smiles>

carboxyethylarginine
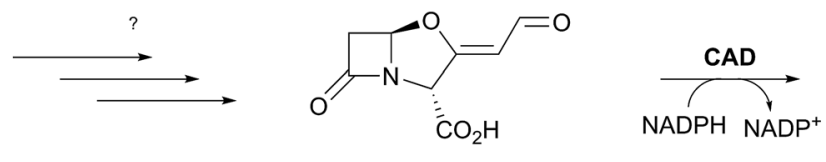

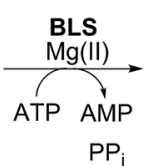

$P_{i}$<smiles>CC(C)(C)[Si](C)(C)C(=O)O[Mg]</smiles><smiles>N=C(N)NCC[C@@H](O)[C@H](C(=O)O)N1CCC1=O</smiles>

guanidino-proclavaminic acid

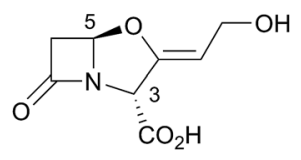

clavulanic acid

Fig. 9 Biosynthetic scheme for clavulanic acid formation showing the trifunctional role of clavaminic acid synthase (CAS). Note that not all cofactors, co-substrates, and products are shown. CEAS: carboxyethylarginine synthase; BLS: $\beta$-lactam synthetase; PAH: proclavaminate amidino hydrolase; CAD: clavaldehyde dehydrogenase; ThDP: thiamine diphosphate. 
site to catalyse multiple reactions is precedented with other 2OG oxygenases, ${ }^{22}$ CAS is remarkable because of the three distinct types of reactions it catalyses (Fig. 10). Further, one of these - the first hydroxylation - occurs with a guanidine side chain, whereas the latter two - bicyclisation and desaturation occur with an amino side chain. Thus, the role of PAH appears to be to substitute the substrate side chain in order to enable CAS to catalyse two additional reactions. Note the amino analogue of proclavaminic acid is neither an efficient inhibitor, nor a substrate of CAS. ${ }^{\mathbf{1 3 4}}$

The combined crystallographic and solution studies have yielded insight into the mechanisms of CAS. A crystal structure of the complex of CAS1 (one of two CAS isozymes in Streptomyces spp. ${ }^{136}$ ) with Fe(II) and 2-OG reveals the characteristic $2 \mathrm{OG}$ oxygenase core fold based on a distorted double stranded $\beta$-helix fold, consisting of eight $\beta$-strands, enveloped by two $\alpha$-helical regions (Fig. 11). ${ }^{\mathbf{1 4 4}}$ While there is little overall sequence similarity between CAS and the penicillin/ cephalosporin $\beta$-lactam biosynthesis enzymes, DAOCS/DACS and IPNS, the similar overall structure and arrangement of active site motifs implies that, as with all characterised $2 \mathrm{OG}$ oxygenases, they ultimately arise from divergent evolution. There is more sequence similarity between CAS and the $2 \mathrm{OG}$ oxygenases of carbapenem biosynthesis, including CarC, ${ }^{\mathbf{1 4 5}}$

A)
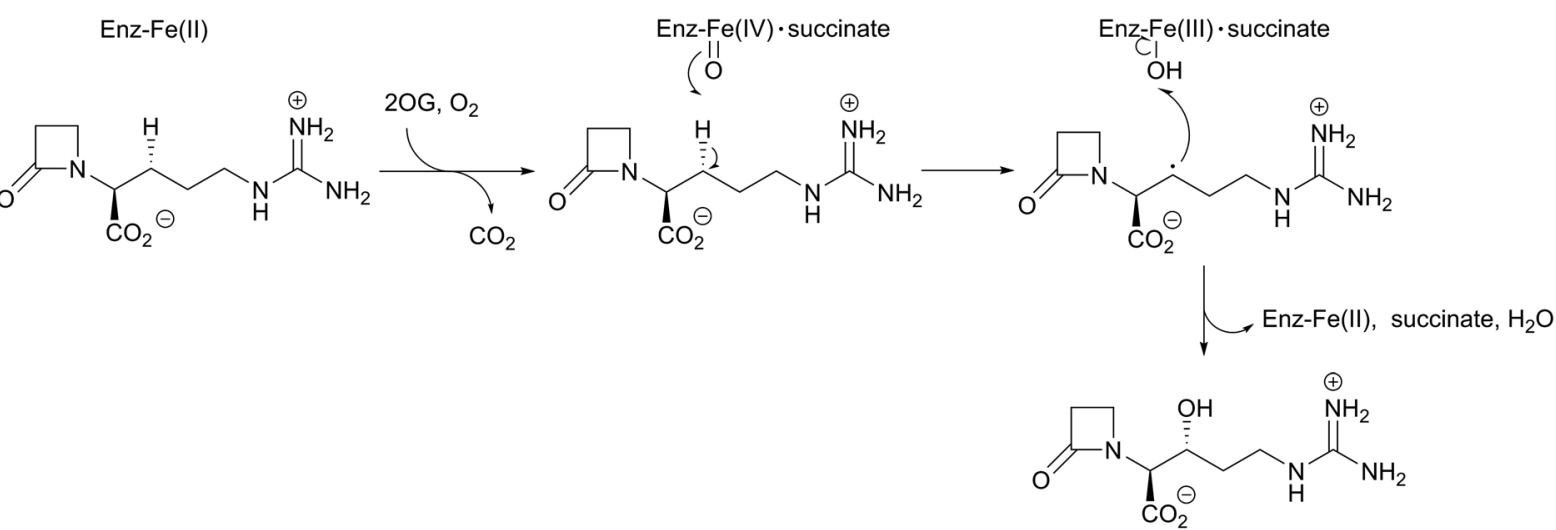

B)
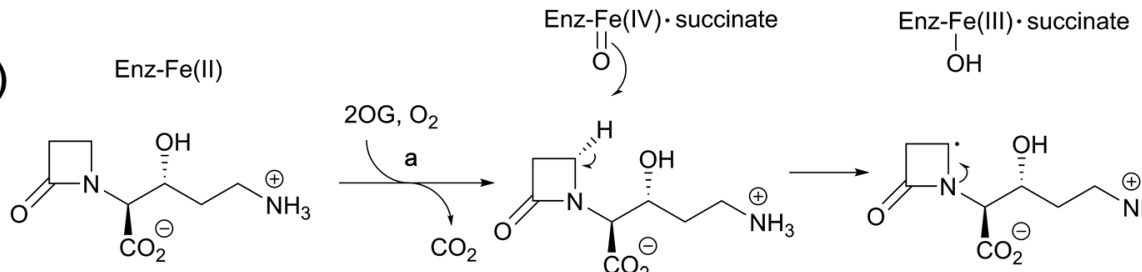<smiles>CC(C)[C@H](C)CC(=O)O[Na]</smiles><smiles>CC(CC(C)C(=O)O[Na])OC(=O)O</smiles>

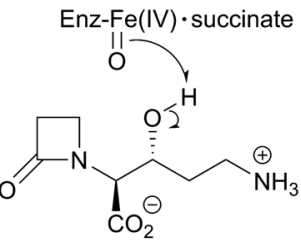

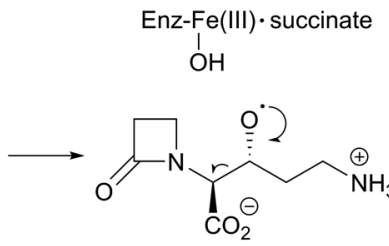

Enz-Fe(III)· succinate<smiles>N[CH]C[C@@H](O)[C@@H](C(=O)[O-])N1[CH]CC1=O</smiles>

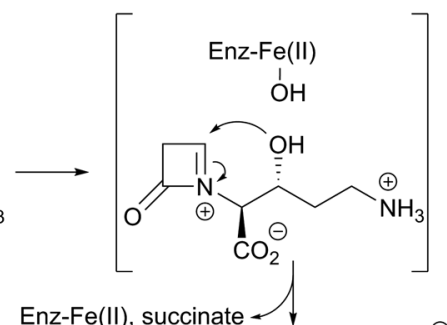



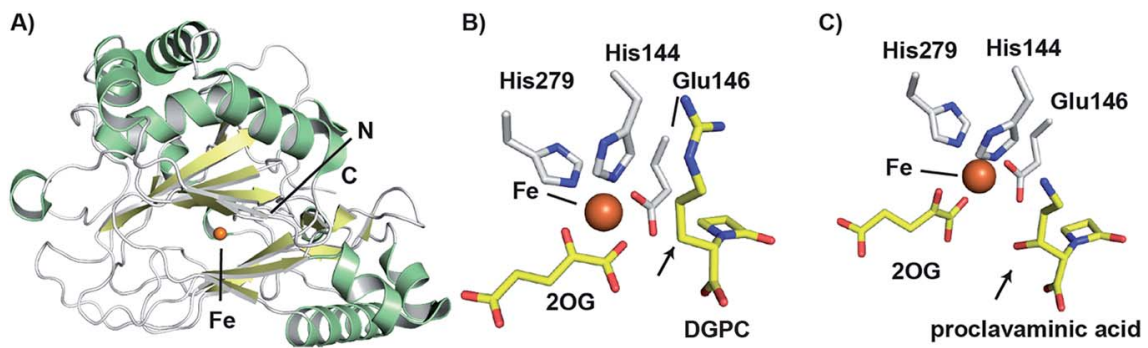

Fig. 11 Views from structures of clavaminic acid synthase (CAS). (A) View from a crystal structure of CAS1 (PDB 1DS1) ${ }^{145}$ highlighting the core double-stranded $\beta$-helix fold (yellow). (B) View of the CAS1 active site with bound deoxyguanidinoproclavaminic acid (DGPC; PDB 1GVG), ${ }^{147}$ showing the orientation of the position to be hydroxylated (C-3) towards the metal (arrowed). Use of a Glu (rather than the more typical Asp) to bind to the iron may contribute to the catalytic flexibility of CAS. Note this structure was obtained using $\mathrm{NO}$ in place of $\mathrm{O}_{2}$. (C) View from the active site of a crystal structure of CAS1 with proclavaminic acid (PDB 1DRT). ${ }^{145}$ Note that the hydroxyl group is oriented towards the iron (arrowed), consistent with a mechanism in which the hydroxyl group hydrogen atom is abstracted by a ferryl species.

suggesting a closer evolutionary relationship between these two sets of $20 \mathrm{O}$ oxygenases.

The CAS structures revealed that iron binding is mediated by the side chains of His144, Glu146, and His279; the presence of an HXE $\cdots \mathrm{H}$ motif in CAS rather than an HXD $\cdots \mathrm{H}$ motif, as in IPNS and DAOCS is notable. The presence of a glutamyl residue in this motif, in place of the more commonly observed aspartyl residue is proposed to be related to the ability of CAS to catalyse multiple reactions in a single active site. ${ }^{145}$ As glutamyl residues are longer than aspartyl residues by a methylene unit, the position of the iron center may be relatively more flexible, which may permit the enzyme to catalyse different oxidation reactions with its three structurally distinct substrates.

As with other $2 \mathrm{OG}$ oxygenases (e.g. DAOCS - see above), ${ }^{106}$ bidentate binding of $2 \mathrm{OG}$ to the metal center is proposed to be followed by that of substrate proximate to the metal, an event which weakens binding of a metal-ligated water, so promoting ligation of dioxygen to the metal. An ordered sequential mechanism is supported by spectroscopic studies with CAS. ${ }^{146}$ Notably, the orientations of water and the 2OG 1-carboxylate around the metal center were noted to be reversed relative to what was observed in the DAOCS crystal structure. Studies using nitric oxide, as a mimic of dioxygen, revealed loss of a metal ligated water and rearrangement of the $2 \mathrm{OG} \mathrm{C-1}$ carboxylate on nitric oxide complexation. ${ }^{147}$ The precise mechanistic significance of this for CAS catalysis has yet to be defined, but analogous rearrangements are proposed with some other $2 \mathrm{OG}$ oxygenases, but in other cases (e.g. DAOCS) appear not to operate. ${ }^{24}$

Crystal structures have also been solved for CAS complexed with its substrates proclavaminic acid and deoxyguanidinoproclavaminate (DGPC), as well as the DGPC mimic $N$-acetylarginine. ${ }^{145,147}$ The binding positions observed for DGPC and $N$-acetylarginine are such that the 3-pro- $R$ hydrogen atom is oriented towards the metal center, apparently allowing for its abstraction by the ferryl intermediate (Fig. 11B). ${ }^{145,147}$ The guanidino group of DGPC (and $N$-acetylarginine) appears to be snugly bound at the active site, being oriented to interact with the side chains of two aspartyl residues, while the $\beta$-lactam ring (or $N$-acetyl group) is positioned in a hydrophobic pocket. ${ }^{145,147}$
Thus, the CAS catalysed hydroxylation reaction appears to be enabled by precise enzyme-substrate interactions, consistent with solution studies on the high degree of stereoselectivity for the CAS catalysed hydroxylation of DGPC and NAA. ${ }^{148}$

While Arg297 is positioned so as to interact with the carboxylate of DGPC, the position of this residue is shifted somewhat in the structure with proclavaminic acid (Fig. 11C) so as to hydrogen bond with the hydroxyl group of the substrate for bicyclisation. ${ }^{145,147}$ Further, the amino group of proclavaminic acid does not appear positioned to interact directly with the aspartyl residues which are involved in binding to the guanidino group of the DGPC, but may interact with them through water molecules. ${ }^{145,147}$ Overall, the available structures imply proclavaminic acid is bound less precisely in the active site possibly reflecting conformational changes during dihydroclavaminic acid formation. Studies using labelled proclavaminic acid have shown selective loss of the 4-pro- $R \beta$-lactam hydrogen during oxazolidine ring formation, i.e. reaction occurs with retention of stereochemistry ${ }^{149}$ Modelling studies have led to the proposal that the ferryl intermediate first abstracts a hydrogen from the alcohol of proclavaminic acid; 1,5hydrogen abstraction may then remove the $\beta$-lactam C-4 hydrogen so enabling subsequent oxazolidine ring formation, potentially via a radical retro aldol fragmentation followed by a 1,3-dipolar reaction (Fig. 10). ${ }^{150}$ Information on the CAScatalysed desaturation is hindered by lack of a dihydroclavaminic acid complex structure, but solution studies reveal the CAS reaction proceeds with retention of stereochemistry $^{141}$ and a stepwise process seem most probable (Fig. 10).

Given the clinical importance of clavulanic acid as an inhibitor of serine $\beta$-lactamases, there is interest in exploiting the clavam biosynthetic pathway to generate clavulanic acid analogues. Studies with CAS have demonstrated flexibility in terms of the substrates accepted by this enzyme, perhaps unsurprisingly given the catalytic flexibility of this enzyme. Notably, given the development of avibactam, ${ }^{7,151-154}$ CAS is able to generate a $\gamma$-lactam derivative of clavaminic acid from the $\gamma$ lactam variant of proclavaminic acid. ${ }^{155}$ Furthermore, CAS stereospecifically hydroxylates DGPC substrate analogues 
lacking a $\beta$-lactam ring, e.g. $\mathrm{N}$-acetylarginine and $\mathrm{N}$-acetylornithine, with alkene formation being observed in some cases, reflecting the flexibility in CAS catalysis. ${ }^{\mathbf{1 3 3 , 1 4 1 , 1 4 8}}$ However, as the biosynthetic steps leading from clavaminic acid to clavulanic acid are unclear, it is also unclear whether the enzymes involved in these steps would tolerate such substitutions at an early stage in the pathway. Hence, engineering the end of the biosynthesis pathway to add functional groups to clavulanic acid may be more productive.

\section{2OG oxygenases in carbapenem biosynthesis}

Biosynthetic studies of the carbapenems have primarily focused on the simplest carbapenem, (5R)-carbapen-2-em-3-carboxylic acid, and the more structurally complex and potent antibiotic thienamycin., ${ }^{\mathbf{4 1 1}, 13}$ The biosynthetic pathways to these two carbapenems may initially follow a common pathway, but diverge in later steps involving the desaturation and epimerisation of the five-membered ring, as well as the functionalisation at C-2 and C-6 as present in thienamycin., ${ }^{4,11,13,156,157}$

The committed step of both pathways likely involves a decarboxylative aldol type reaction of malonyl-CoA with pyrroline-5-carboxylate, as catalysed by the crotonase-fold enzyme CarB/ThnE. ${ }^{158,159}$ CarB/ThnE have been shown to accept multiple substrate analogues and are amenable to engineering to produce multiple $\beta$-amino acids, many of which can be converted to $\beta$-lactams. ${ }^{\mathbf{1 5 8 , 1 6 0}}$ In an analogous manner as occurring in the biosynthesis of clavulanic acid, but to give a bicycle, the carbapenem ring is formed via an ATP-dependent condensation catalysed by CarA/ThnM, forming $(3 S, 5 S)$ carbapenam-3-carboxylic acid. The final steps in the biosynthesis of $(5 R)$-carbapen-2-em-3-carboxylic acid are apparently catalysed by the 2OG-dependent oxygenase CarC. CarC catalyses the unusual epimerisation at the $\mathrm{C}-5$ position, then desaturates the resultant $(3 S, 5 R)$-carbapenam-3-carboxylic acid between C-2 and C-3 to give (5R)-carbapen-2-em-3-carboxylic acid (Fig. 12).,11,13

Although recent studies have clarified key aspects of thienamycin biosynthesis, the overall thienamycin biosynthetic pathway is not fully elucidated. The biosynthetic gene cluster for thienamycin does not encode a close CarC homologue, ${ }^{\mathbf{1 6 1 , 1 6 2}}$ and the mechanisms underlying carbapenam C-5 epimerisation and double bond formation in thienamycin biosynthesis are unclear. However, the pathways by which the C-2 and C-6 side chains are formed and functionalised have been elucidated, uncovering interesting chemistry involving 2 OG oxygenases. ${ }^{156}$

Freeman et al. demonstrated that the C-2 cysteamine substituent of thienamycin is derived from coenzyme A via the action of hydrolytic enzymes ThnR, ThnH, and ThnT (Fig. 12). ${ }^{157}$ Whilst ThnR and ThnH sequentially degrade coenzyme A to pantetheine, ThnT degrades the pantetheinyl group to cysteamine, but only once it is covalently attached to the carbapenem core. ${ }^{157} \mathrm{~N}$-Acetylated thienamycin derivatives have been described; these are proposed to be formed through the action of the acetyltransferase ThnF. ${ }^{157}$ Further derivatives have been isolated which show desaturation of the C-2 cysteamine ethyl group and/or oxidation of the sulfur. Incubation of predicted substrates with the 2 OG oxygenase ThnG showed that it catalyses sequential desaturation and sulfoxidation of the cysteamine side chain of deshydroxy $\mathrm{N}$-acetylthienamycin (also referred to as PS-5; Fig. 12). ${ }^{156}$

The radical $S$-adenosylmethionine (SAM) enzyme ThnK is responsible for incorporation of the ethyl substituent at C-6 of thienamycin, in a mechanism involving two sequential radicalmediated methylation reactions. ${ }^{163}$ The $2 \mathrm{OG}$ oxygenase ThnQ has been shown to modify the C-6 ethyl group, by catalysing (8R)-hydroxylation (Fig. 12). ${ }^{\mathbf{1 5 6}}$ Disruption of the ThnQ homolog involved in the biosynthesis of MM 4550 resulted in accumulation of an unhydroxylated product. ${ }^{164}$ Some carbapenems have different C-6 side chains, such as an (8S)-hydroxyl group or an $(8 S)$-sulfate group (as seen in MM 4550). ${ }^{4}$ The epimerisation of the 8-hydroxyl group in MM 4550 is proposed to be catalysed by Cmm17, an enzyme homologous to the enoyl-CoA hydratases. ${ }^{157}$ The sulfotransferase $\mathrm{CmmSu}$ is proposed to catalyse sulfate formation, as supported by gene disruption studies. ${ }^{164}$

While these recent reports have greatly enhanced the understanding of the biosynthesis of the complex carbapenems, questions remain regarding some of the carbapenem biosynthetic steps. The mechanisms of desaturation and epimerisation of the five-membered ring in thienamycin biosynthesis are of particular interest. Further questions remain regarding the overall order in which modifications occur to the five-membered ring, the $\mathrm{C}-2$, and the C- 6 side chains. The enzymatic steps involved in the modifications seen in some other carbapenems (e.g., the C-6 hydroxyisopropylidene group of the asparenomycins) ${ }^{4,165,166}$ also remain to be elucidated.

\subsection{CarC - a carbapenem synthase}

In 1996, McGowan et al. described the gene cluster responsible for the biosynthesis of the simplest carbapenem (5R)-carbapen2-em-3-carboxylic acid from Erwinia carotovora (now Pectobacterium carotovorum). ${ }^{167}$ In particular, homologies between CarA and CarC and the clavulanic acid biosynthetic enzymes $\beta$ lactam synthetase and CAS were noted. ${ }^{167}$ The role of CarC in carbapenem biosynthesis was supported the following year by mutational analysis. ${ }^{168}$ CarC is proposed to catalyse both epimerisation and desaturation of (3S,5S)-carbapenam-3carboxylic acid, forming (5R)-carbapen-2-em-3-carboxylic acid [as well as $(3 S, 5 R)$-carbapenam-3-carboxylic acid]. ${ }^{169}$ Substrate studies demonstrated that $(3 S, 5 R)$-carbapenam-3-carboxylic acid could also be converted to (5R)-carbapen-2-em-3carboxylic acid by CarC, suggesting that the epimerisation activity of CarC precedes the desaturation activity (Fig. 13). ${ }^{\mathbf{1 7 0 , 1 7 1}}$

Crystallographic studies of CarC have revealed the doublestranded $\beta$-helix core typical of the $2 \mathrm{OG}$ oxygenases. ${ }^{172}$ The active site $\mathrm{Fe}(\mathrm{II})$ species was bound by a conserved 2-His-1carboxylate triad as in IPNS/DAOCS, involving the side chains of His101, Asp103, and His251 (Fig. 14). 2OG was bound to the iron via the 2-keto and 1-carboxylate groups, while the C-5 carboxylate of $2 \mathrm{OG}$ forms an electrostatic interaction with the side chain of Arg263. ${ }^{172}$ Given the poor stability of $(3 S, 5 S)$ - 


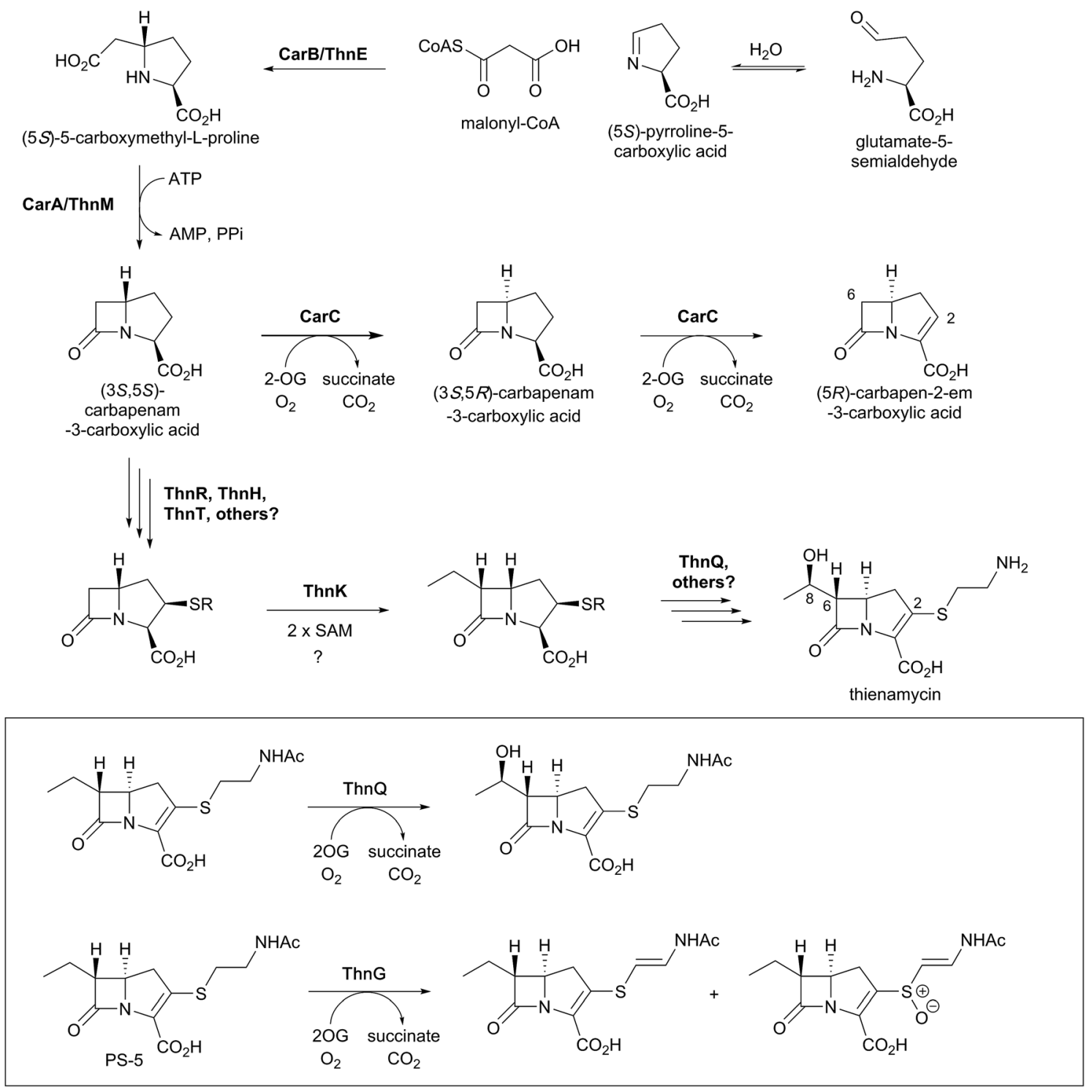

Fig. 12 Biosynthetic scheme for carbapenem formation showing the roles of 2OG oxygenases. Carbapenem synthase (CarC) catalyses both epimerisation and desaturation steps in the biosynthesis of (5R)-carbapen-2-em-3-carboxylic acid. ThnQ and ThnG have (at least) roles in carbapenem side chain modification during thienamycin biosynthesis. Note that not all co-factors, co-substrates, and products are shown.

carbapenam-3-carboxylic acid, a structure of CarC was first solved with bound $\mathrm{L}-\mathrm{N}$-acetylproline acting as a substrate analogue. ${ }^{172}$ While it was not possible to conclusively assign the orientation of $\mathrm{L}-\mathrm{N}$-acetylproline in this structure, modeling studies allowed the binding interactions of both $(3 S, 5 S)$ - and $(3 S, 5 R)$-carbapenam-3-carboxylic acid with CarC to be studied. ${ }^{172}$ A later crystal structure of CarC was solved with bound $(3 S, 5 S)$-carbapenam-3-carboxylic acid, in which two loops near the active site (which were disordered in previous structures) could be modeled. ${ }^{173}$ The orientation of $(3 S, 5 S)$ carbapenam-3-carboxylic acid in this structure was such that the C-5 hydrogen atom was oriented towards the active site iron. ${ }^{173}$

Labeling studies, in which Serratia marcescens was treated with deuterium- and tritium-labeled L-prolines, indicated that an isotopic label is retained at the C-5 position of $(3 S, 5 S)$ - carbapenam-3-carboxylic acid, but lost at the $\mathrm{C}-5$ position of the diastereomer (and initial CarC product) (3S,5R)-carbapenam-3carboxylic acid. ${ }^{\mathbf{1 7 4}}$ This led to the proposal that the epimerisation step involves the abstraction of the hydrogen atom at the C-5 position; computational studies suggested that formation of a C-5 radical was energetically favourable, most likely through hydrogen abstraction by the ferryl radical (followed by stereochemical inversion). ${ }^{\mathbf{1 7 5}}$ Further density functional theory calculations and in silico docking studies were consistent with such a mechanism, and suggested that the phenol group of a tyrosine residue may act as a hydrogen atom donor on the other face of the C-5 radical, thereby completing the epimerisation step. ${ }^{\mathbf{1 7 6 , 1 7 7}}$ Based on a crystal structure of CarC with substrate $(3 S, 5 S)$-carbapenam-3-carboxylic acid (as well as mutational analysis), Tyr165 was proposed to play this role. ${ }^{172,173}$ The epimerisation step catalysed by CarC is redox 


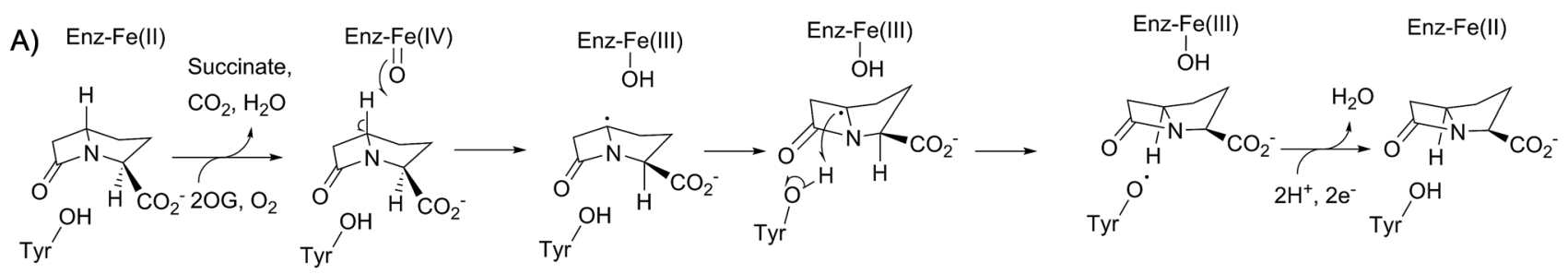

B)
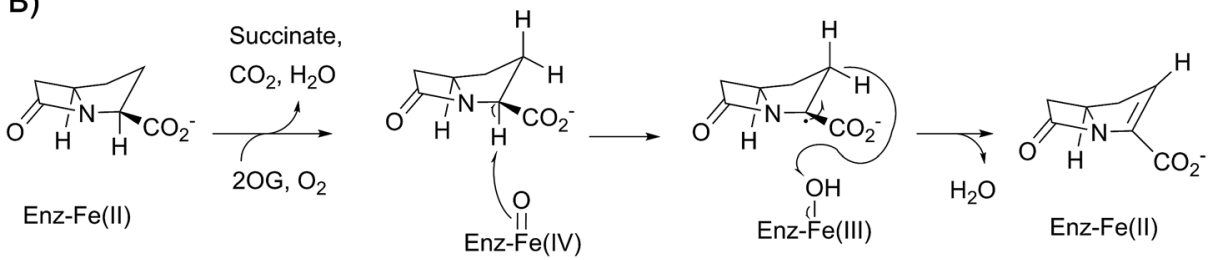

Fig. 13 Proposed outline mechanisms for the two reactions involving CarC. (A) C5 inversion of stereochemistry; (B) oxidative C2-C3 desaturation.
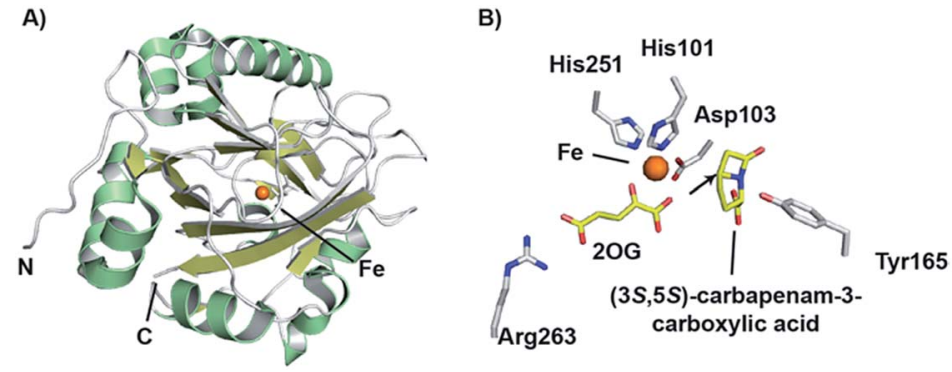

Fig. 14 Views from structures of carbapenem synthase (CarC). (A) Overall view of a crystal structure of CarC (PDB 1NX4) ${ }^{172}$ showing the doublestranded $\beta$-helix fold. (B) View of the active site from a crystal structure of CarC with bound substrate (3S,5S)-carbapenam-3-carboxylic acid (PDB 4OJ8). ${ }^{173}$ Note that the $\mathrm{C}-5$ hydrogen atom is likely abstracted by the ferryl iron species in the epimerisation step, with Tyr165 likely acting as the hydrogen atom donor on the other face.

neutral, and so it is possible that the desaturation step may employ the same ferryl species as that involved in the epimerisation step. However, rapid-kinetic and spectroscopic studies indicate that the epimerisation step is likely stoichiometric, occurring with oxidation of $\mathrm{Fe}$ (II) to $\mathrm{Fe}$ (III). ${ }^{173}$ Substitution of Tyr165 with a phenylalanine residue yielded an enzyme that catalyses catalytic substrate oxidation. ${ }^{173}$ Therefore, desaturation may require the generation of a new ferryl species, thus probably requiring a second catalytic cycle involving 2OG. The desaturation step, a more typical reaction catalysed by a $20 \mathrm{OG}$ oxygenase, may involve initial abstraction of a hydrogen atom at $\mathrm{C}-2 .{ }^{173}$

\section{Potential roles of $20 \mathrm{O}$ oxygenases in the biosynthesis of monocyclic $\beta$ - lactams}

Pioneering reports informed on the amino acid origins, role of peptide synthetases, and stereochemistry of ring formation in monocyclic $\beta$-lactam biosynthesis., ${ }^{4,13,178,179}$ However, until recently, relatively little has been described regarding the enzymology of the biosynthesis of monocyclic $\beta$-lactams. At least in the case of some monocyclic $\beta$-lactams, i.e. the monobactams and tabtoxin, sequencing studies have implicated $20 \mathrm{OG}$ oxygenases in their biosynthetic pathways, though likely not in actual $\beta$-lactam formation., ${ }^{4,13,180-182}$ Recent reports have informed on biosynthesis of the monocyclic $\beta$-lactams, highlighting chemically interesting mechanisms of cyclisation. ${ }^{181,182}$ Notably, whilst the $\beta$-lactam rings of the nocardicins ${ }^{163}$ and sulfazecin $^{182}$ are both formed in reactions catalysed by nonribosomal peptide synthetases (NRPS), the precise mechanisms of $\beta$-lactam formation differ for these two $\beta$-lactam antibiotics as described below.

The biosynthesis of nocardicin begins with NRPS proteins NocA and NocB. ${ }^{181,183}$ Based on the analysis of the five adenylation domains of these two proteins, a pentapeptide product/intermediate was predicted with a sequence of L-pHPG-L-Arg-D-pHPG-L-Ser-L-pHPG (pHPG, $\quad p$-hydroxyphenylglycine). ${ }^{183} \quad \beta$-Lactam formation occurs while the nascent peptide chain is covalently attached to NocB (Fig. 3). ${ }^{181} \beta$-Lactam formation was demonstrated to involve dehydration of the serine residue (as part of a NocB tetrapeptide peptide chain) bound to peptidyl carrier protein 

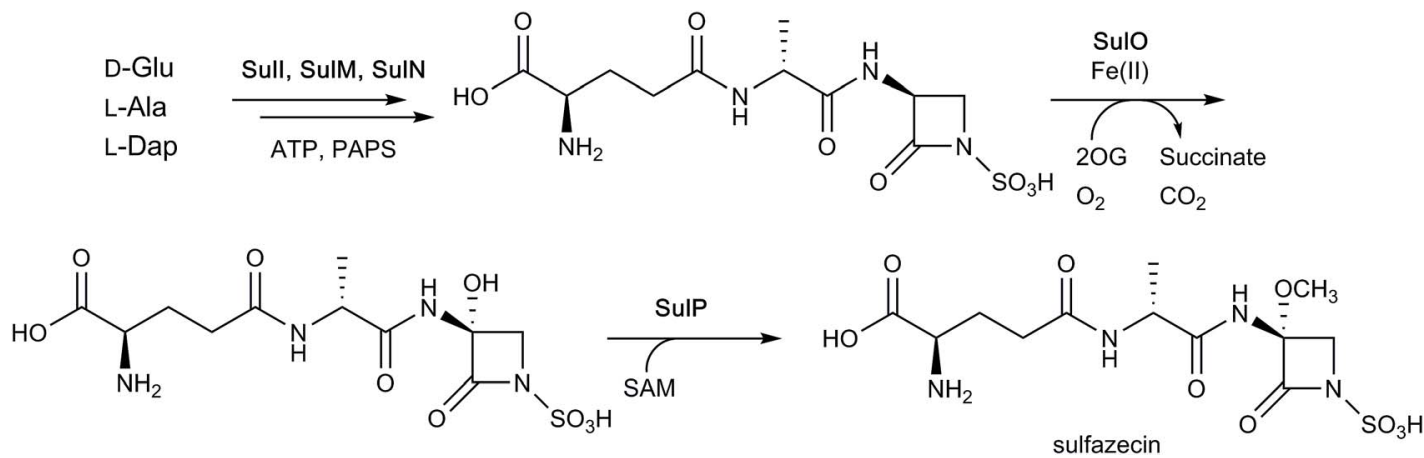

Fig. 15 Final steps of sulfazecin biosynthesis. As shown in Fig. 3, the non-ribosomal peptide synthetases Sull and SulM are responsible for synthesising the sulfazecin peptide scaffold and $\beta$-lactam ring from D-glutamate, L-alanine, and L-2,3-diaminopropionate (L-Dap), while SulN acts as a sulfotransferase using $3^{\prime}$-phosphoadenosine $5^{\prime}$-phosphosulfate (PAPS) as a co-factor. The 2OG-dependent oxygenase SulO then catalyses C-3 hydroxylation, followed by S-adenosylmethionine (SAM)-mediated methylation as catalysed by SulP. ${ }^{182}$ Note that not all co-factors, cosubstrates, and products are shown.

(PCP) domain $\mathrm{PCP}_{4}$, prior to the incorporation of the $C$ terminal pHPG residue. The $\alpha$-amino group of this pHPG residue, while bound to PCP domain 5 as a thioester, can then undergo conjugate addition with the protein-linked dehydroalanine residue. The resultant secondary amino group of the $\mathrm{PCP}_{5}$-bound $\mathrm{pHPG}$ then attacks the thioester link to $\mathrm{PCP}_{4}$, forming the $\beta$-lactam and releasing the nascent peptide chain from $\mathrm{PCP}_{4}$. Finally, following the thioesterasedomain mediated hydrolysis, pro-nocardicin $\mathrm{G}$ is obtained; a further hydrolytic step and tailoring reactions lead to nocardicin A. ${ }^{181}$

While the $\beta$-lactam formation in nocardicin occurs on an NRPS PCP domain, the $\beta$-lactam ring of sulfazecin is proposed to occur via catalysis of an NRPS thioesterase domain. ${ }^{182}$ The NRPSs SulI and SulM, which contain three modules, generate an enzyme-bound tripeptide intermediate, consisting of a D-Glu residue (linked via its $\gamma$-carboxyl group), a D-Ala residue, and a $\mathrm{L}$-2,3-diaminopropionate (Dap or $\beta$-aminoalanine) residue. The 3-amino group of Dap (in its SulM-bound tripeptide form) then undergoes an unusual $N$-sulfonation reaction, as catalysed by SulN, which uses $3^{\prime}$-phosphoadenosine $5^{\prime}$-phosphosulfate as a cosubstrate. The tripeptide is then transferred to a thioesterase domain, which catalyses nucleophilic attack of the sulfonated amino group onto the thioester carbonyl, thereby forming the $\beta$-lactam. ${ }^{182}$ This alternate strategy for $\beta$-lactam formation ( $c f$. nocardicin) is possible as the $\beta$-lactam ring occurs at the $C$-terminus of the substrate, whereas that found in nocardicin occurs within the peptide sequence.

As seen with some cephalosporins (see above), the $\beta$-lactam rings of certain monocyclic $\beta$-lactams (such as sulfazecin and tabtoxin) manifest methoxylation at the C-3 position, ${ }^{4}$ a modification which can decrease susceptibility to some $\beta$-lactamases. ${ }^{184,185}$ The biosynthetic gene cluster associated with sulfazecin was noted to encode putative 2OG oxygenase, SulO, and methyltransferase, SulP. ${ }^{184,185}$ As indicated above, the NRPSs SulI and SulM and sulfotransferase SulN catalyse the formation of desmethoxysulfazecin. Addition of SulO and SulP to this in vitro reconstitution of the biosynthetic pathway (with added 2OG, ammonium ferrous sulfate, and ascorbate) yielded sulfazecin, confirming the role of SulO in monobactam C-3 hydroxylation (Fig. 15). ${ }^{182}$ The tabtoxin gene cluster encodes for putative $2 \mathrm{OG}$ oxygenase TblC, which likely plays an analogous role in tabtoxin biosynthesis. ${ }^{186}$

\section{Conclusions}

In the period following Arnstein's breakthrough proposal ${ }^{26}$ for the peptide origin of the penicillins and Abraham's direct evidence $^{27}$ for the role of $\mathrm{L}, \mathrm{L}, \mathrm{D}-\mathrm{ACV}$ (and by implication an oxidative mechanism for penicillin formation) very considerable advances have been made in our understanding of $\beta$-lactam biosynthesis. IPNS was isolated and shown to operate via a chemically remarkable mechanism..$^{22}$ ATP dependent synthetases that catalyse $\beta$-lactam formation from $\beta$-amino acids have been identified and peptide synthetase templated $\beta$-lactam formation via thioester reactions ${ }^{180,181}$ has been shown to operate for at least two classes of monocyclic $\beta$-lactams. Aside from the central role of IPNS, 2OG oxygenases have been shown to play roles in the biosynthesis of bicyclic $\beta$-lactams (DAOCS) and in modifying both monocyclic and bicyclic $\beta$-lactams, sometimes by chemically interesting processes (especially the DAOCS, CAS, and CarC reactions). ${ }^{4}$ The biosynthetic work, including on the $2 \mathrm{OG}$ oxygenase superfamily members, has been justified in part on the basis that it may help enable improved routes to already used antibiotics (e.g. by enabling fermentation of carbapenems) and make synthetically challenging structures of interest for testing as antibiotics more accessible. Despite ongoing efforts to engineer cephalosporin biosynthesis, these 'translational' outcomes have yet to be realised. This is likely in part due to commercial and regulatory considerations associated with the introduction of new manufacturing procedures for (new) antibiotics, coupled with the success of classical empirical strain optimisation and lack of knowledge of 'indirect' limiting molecular factors for the highly efficient large scale fermentation and isolation of relatively labile small molecules. Recent work on metabolic engineering, e.g. TCA cycle glyoxylate metabolism (as well as 
deleting $\beta$-lactamases) holds promise for increasing $\beta$-lactam antibiotic production yields. ${ }^{119,187,188}$

Combining these approaches with biosynthetic pathway engineering may be productive. The results to date on $\beta$-lactam biosynthesis do, however, mean that focused efforts to engineer $\beta$-lactam biosynthesis, e.g. by 'rewiring' the penicillin/ cephalosporin pathway to produce new generation cephalosporins via modification of ACVS/IPNS/DAOCS, could at least proceed in the light of detailed knowledge of how the relevant enzymes work. Future biocatalytic research could also explore the use of modified enzymes in combination with nonenzymatic synthetic chemistry to access modified $\beta$-lactams of interest in the field of antibacterials and beyond. Engineering involving coupling the modular nature of peptide synthetase mediated $\beta$-lactam biosynthesis with the tailoring capabilities of $2 \mathrm{OG}$ oxygenases is one potential avenue.

It is, however, important to note that although the basic work on the enzymes of $\beta$-lactam biosynthesis has not (yet) delivered breakthroughs in the antibacterial field, the chemical interest driven work on enzyme mechanisms and structures has been enabling in other fields. The structural studies on IPNS and the $\beta$-lactam modifying $2 \mathrm{OG}$ oxygenases ${ }^{28-30,145}$ led to the identification of apparently homologous enzymes in most aerobic organisms. Some of these are used in biocatalysis, others are important in plant signalling ('ethyleneforming-enzymes') and as agrochemical targets (gibberellin biosynthesis oxygenases), whilst many others play crucial roles in animal biology, notably in post translational protein modifications and in the regulation of nucleic acid and protein biosynthesis. ${ }^{22}$ Inhibitors for human $20 \mathrm{O}$ dependent prolyl-hydroxylases, which play a critical role in the cellular response to hypoxia, are presently in late stage clinical trials for the treatment of anaemia. ${ }^{\mathbf{1 8 9}}$ Hence, at least, the work on the oxygenases of $\beta$-lactam biosynthesis is a nice example of how curiosity driven research on chemically interesting natural products can help open new fields of medicinal relevance.

\section{Conflicts of interest}

The authors declare no conflicts of interest.

\section{Acknowledgements}

We thank the Biotechnology and Biological Sciences Research Council (BBSRC), the Engineering and Physical Sciences Research Council (EPSRC) (for a studentship to J. K. via the Synthesis for Biology and Medicine, Centre for Doctoral Training, and a Clarendon Scholarship), the Medical Research Council, the Innovative Medicines Initiative, and the Wellcome Trust, for funding our work on $\beta$-lactams. P. R. thanks the Deutsche Akademie für Naturforscher Leopoldina, Germany, for funding a postdoctoral fellowship. We also thank and acknowledge our coworkers and those in other groups for their work on $\beta$-lactam biosynthesis and apologise for incomplete citations in this brief review.

\section{References}

1 B. Hamad, Nat. Rev. Drug Discov., 2010, 9, 675.

2 K. Tahlan and S. E. Jensen, J. Antibiot., 2013, 66, 401.

3 K. Bush and P. A. Bradford, Cold Spring Harbor Perspect. Med., 2016, a025247.

4 R. B. Hamed, J. R. Gomez-Castellanos, L. Henry, C. Ducho, M. A. McDonough and C. J. Schofield, Nat. Prod. Rep., 2013, 30, 21.

5 M. Babic, A. M. Hujer and R. A. Bonomo, Drug Resist. Updates, 2006, 9, 142.

6 D. A. Burnett, Curr. Med. Chem., 2004, 11, 1873.

7 D. Y. Wang, M. I. Abboud, M. S. Markoulides, J. Brem and C. J. Schofield, Future Med. Chem., 2016, 8, 1063.

8 G. Ozcengiz and A. L. Demain, Biotechnol. Adv., 2013, 31, 287. 9 C. C. Muniz, T. E. C. Zelaya, G. R. Esquivel and F. J. Fernandez, Rev. Latinoam. Microbiol., 2007, 49, 88.

10 K. H. Baggaley, A. G. Brown and C. J. Schofield, Nat. Prod. Rep., 1997, 14, 309.

11 N. J. Kershaw, M. E. C. Caines, M. C. Sleeman and C. J. Schofield, Chem. Commun., 2005, 4251.

12 C. J. Schofield, J. E. Baldwin, M. F. Byford, I. Clifton, J. Hajdu, C. Hensgens and P. Roach, Curr. Opin. Struct. Biol., 1997, 7, 857.

13 C. A. Townsend, Curr. Opin. Chem. Biol., 2016, 35, 97.

14 J. E. Baldwin and E. Abraham, Nat. Prod. Rep., 1988, 5, 129.

15 J. E. Baldwin and M. Bradley, Chem. Rev., 1990, 90, 1079.

16 S. S. Weber, R. A. L. Bovenberg and A. J. M. Driessen, Biotechnol. J., 2012, 7, 225.

17 R. P. Elander, Appl. Microbiol. Biotechnol., 2003, 61, 385.

18 T. R. M. Barends, H. Yoshida and B. W. Dijkstra, Curr. Opin. Biotechnol., 2004, 15, 356.

19 A. A. Brakhage, Q. Al-Abdallah, A. Tüncher and P. Spröte, Phytochemistry, 2005, 66, 1200.

20 R. D. G. Cooper, Bioorg. Med. Chem., 1993, 1, 1.

21 Y. Aharonowitz and G. Cohen, Annu. Rev. Microbiol., 1992, 46, 461.

22 P. J. Rutledge, in 2-Oxoglutarate-Dependent Oxygenases, ed. R. P. Hausinger and C. J. Schofield, RSC, Cambridge, 2015, pp. 1-487.

23 S. C. Peck and W. A. v. d. Donk, J. Biol. Inorg Chem., 2017, 22, 381.

24 I. J. Clifton, M. A. McDonough, D. Ehrismann, N. J. Kershaw, N. Granatino and C. J. Schofield, J. Inorg. Biochem., 2006, 100, 644.

25 J. E. Baldwin and C. J. Schofield, in The Chemistry of $\beta$ lactams, ed. M. I. Page, Springer, Berlin/Heidelberg, 1992, pp. 1-78.

26 H. R. V. Arnstein and D. Morris, Biochem. J., 1960, 76, 357. 27 P. A. Fawcett, J. J. Usher, J. A. Huddleston, R. C. Bleaney, J. J. Nisbet and E. P. Abraham, Biochem. J., 1976, 157, 651.

28 P. L. Roach, I. J. Clifton, V. Fulop, K. Harlos, G. J. Barton, J. Hajdu, I. Andersson, C. J. Schofield and J. E. Baldwin, Nature, 1995, 375, 700.

29 P. L. Roach, I. J. Clifton, C. M. H. Hensgens, N. Shibata, C. J. Schofield, J. Hajdu and J. E. Baldwin, Nature, 1997, $387,827$. 
30 K. Valegard, A. C. V. Terwisscha Scheltinga, M. D. Lloyd, T. Hara, S. Ramaswamy, A. Perrakis, A. Thompson, H. J. Lee, J. E. Baldwin, C. J. Schofield, J. Hajdu and I. Andersson, Nature, 1998, 394, 805.

31 I. Andersson and K. Valegard, in 2-Oxoglutarate-Dependent Oxygenases, ed. R. P. Hausinger and C. J. Schofield, RSC, Cambridge, 2015, pp. 385-400.

$32 \mathrm{~J}$. Myllyharju, in 2-Oxoglutarate-Dependent Oxygenases, ed. R. P. Hausinger and C. J. Schofield, RSC, Cambridge, 2015, pp. 149-168.

33 S. E. Wilkins, E. Flashman, J. S. Scotti, R. J. Hopkinson, R. Chowdhury and C. J. Schofield, in 2-OxoglutarateDependent Oxygenases, ed. R. P. Hausinger and C. J. Schofield, RSC, Cambridge, 2015, pp. 169-209.

34 T. A. Müller and R. P. Hausinger, in 2-OxoglutarateDependent Oxygenases, ed. R. P. Hausinger and C. J. Schofield, RSC, Cambridge, 2015, pp. 246-262.

35 P. Ø. Falnes and A. Y. Yen Ho, in 2-Oxoglutarate-Dependent Oxygenases, ed. R. P. Hausinger and C. J. Schofield, RSC, Cambridge, 2015, pp. 275-288.

36 R. J. A. Wanders, S. Ferdinandusse, M. S. Ebberink and H. R. Waterham, in 2-Oxoglutarate-Dependent Oxygenases, ed. R. P. Hausinger and C. J. Schofield, RSC, Cambridge, 2015, pp. 338-349.

37 C.-P. Pang, B. Chakravarti, R. M. Adlington, H.-H. Ting, R. L. White, G. S. Jayatilake, J. E. Baldwin and E. P. Abraham, Biochem. J., 1984, 222, 789.

38 X. E. Tamanaha, B. Zhang, Y. Guo, W.-c. Chang, E. W. Barr, G. Xing, J. St. Clair, S. Ye, F. Neese, M. Bollinger Jr and C. Krebs, J. Am. Chem. Soc., 2016, 138, 8862.

39 P. J. Rutledge, in 2-Oxoglutarate-Dependent Oxygenasesm, ed. R. P. Hausinger and C. J. Schofield, RSC, Cambridge, 2015, pp. 414-424.

40 H. R. V. Arnstein and M. E. Clubb, Biochem. J., 1958, 68, 528.

41 K. Tahlan, M. A. Moore and S. E. Jensen, J. Ind. Microbiol. Biotechnol., 2017, 44, 517.

42 M. F. Byford, J. E. Baldwin, C.-Y. Shiau and C. J. Schofield, Chem. Rev., 1997, 97, 2631.

43 W. Kallow, J. Kennedy, B. Arezi, G. Turner and H. von Döhren, J. Mol. Biol., 2000, 297, 395.

44 V. J. Chen, A. M. Orville, M. R. Harpe, C. A. Frolik, K. K. Surerus, E. Münck and J. D. Lipscomb, J. Biol. Chem., 1989, 264, 21677.

45 R. A. Scott, S. Wang and M. K. Eidsness, Biochemistry, 1992, 31, 4596.

46 J. E. Baldwin, R. M. Adlington, S. E. Moroney, L. D. Field and H.-H. Ting, J. Chem. Soc., Chem. Commun., 1984, 984.

47 M. Lundberg, P. E. M. Siegbahn and K. Morokuma, Biochemistry, 2008, 47, 1031.

48 C. D. Brown-Marshall, A. R. Diebold and E. I. Solomon, Biochemistry, 2010, 49, 1176.

49 M. Lundberg, T. Kawatsu, T. Vreven, M. J. Frisch and K. Morokuma, J. Chem. Theory Comput., 2009, 5, 222.

50 M. Lundberg and K. Morokuma, J. Phys. Chem. B, 2007, 111, 9380.
51 P. L. Roach, I. J. Clifton, C. M. H. Hensgens, N. Shibata, A. J. Long, R. W. Strange, S. S. Hasnain, C. J. Schofield, J. E. Baldwin and J. Hajdu, Eur. J. Biochem., 1996, 242, 736.

52 A. J. Long, I. J. Clifton, P. L. Roach, J. E. Baldwin, C. J. Schofield and P. J. Rutledge, Biochem. J., 2003, 372, 687.

53 I. J. Clifton, W. Ge, R. M. Adlington, J. E. Baldwin and P. J. Rutledge, FEBS Lett., 2013, 587, 2705.

54 A. J. Long, I. J. Clifton, P. L. Roach, J. E. Baldwin, P. J. Rutledge and C. J. Schofield, Biochemistry, 2005, 44, 6619.

55 N. I. Burzlaff, P. J. Rutledge, I. J. Clifton, C. M. Hensgens, M. Pickford, R. M. Adlington, P. L. Roach and J. E. Baldwin, Nature, 1999, 401, 721.

56 P. J. Rutledge, N. I. Burzlaff, J. M. Elkins, M. Pickford, J. E. Baldwin and P. L. Roach, Anal. Biochem., 2002, 308, 265.

57 J. E. Baldwin, R. M. Adlington, S. E. Moroney, L. D. Field and H. H. Ting, J. Chem. Soc., Chem. Commun., 1984, 15, 984.

58 A. C. Stewart, I. J. Clifton, R. M. Adlington, J. E. Baldwin and P. J. Rutledge, ChemBioChem, 2007, 8, 2003.

59 C. J. Schofield and Z. H. Zhang, Curr. Opin. Struct. Biol., 1999, 9, 722.

60 M. Sami, T. J. N. Brown, P. L. Roach, C. J. Schofield and J. E. Baldwin, FEBS Lett., 1997, 405, 191.

61 L. A. McNeill, T. J. N. Brown, M. Sami, I. J. Clifton, N. I. Burzlaff, T. D. W. Claridge, R. M. Adlington, J. E. Baldwin, P. J. Rutledge and C. J. Schofield, Chem.Eur. J., 2017, 23, 12815.

62 J. E. Baldwin, G. P. Lynch and C. J. Schofield, Tetrahedron, 1992, 48, 9085.

63 J. M. Blackburn, J. D. Sutherland and J. E. Baldwin, Biochemistry, 1995, 34, 7548.

64 J. E. Baldwin, M. Bradley, S. D. Abbott and R. M. Adlington, Tetrahedron, 1991, 47, 5309.

65 J. E. Baldwin, R. M. Adlington, B. P. Domayne-Hayman, G. Knight and H.-H. Ting, J. Chem. Soc., Chem. Commun., 1987, 1661.

66 A. R. Howard-Jones, J. M. Elkins, I. J. Clifton, P. L. Roach, R. M. Adlington, J. E. Baldwin and P. J. Rutledge, Biochemistry, 2007, 46, 4755.

67 A. Daruzzaman, I. J. Clifton, R. M. Adlington, J. E. Baldwin and P. J. Rutledge, ChemBioChem, 2011, 14, 1881.

68 W. Ge, I. J. Clifton, A. R. Howard-Jones, J. E. Stok, R. M. Adlington, J. E. Baldwin and P. J. Rutledge, ChemBioChem, 2009, 10, 2025.

69 A. Daruzzaman, I. J. Clifton, R. M. Adlington, J. E. Baldwin and P. J. Rutledge, ChemBioChem, 2006, 7, 351.

70 J. E. Baldwin, J. M. Blackburn, M. Sako and C. J. Schofield, J. Chem. Soc., Chem. Commun., 1989, 970.

71 J. E. Baldwin, R. M. Adlington, A. E. Derome, H. H. Ting and N. J. Turner, J. Chem. Soc., Chem. Commun., 1984, 1211.

72 J. E. Baldwin and M. Bradley, Chem. Rev., 1990, 90, 1079.

73 J. E. Baldwin, R. M. Adlington, N. Moss and N. G. Robinson, J. Chem. Soc., Chem. Commun., 1987, 1664.

74 J. E. Baldwin, G. P. Lynch and C. J. Schofield, Tetrahedron, 1992, 48, 9085. 
75 J. E. Baldwin, W. J. Norris, R. T. Freeman, M. Bradley, R. M. Adlington, S. Long-Fox and C. J. Schofield, J. Chem. Soc., Chem. Commun., 1988, 1128.

76 G. A. Bahadur, J. E. Baldwin and J. J. Usher, J. Am. Chem. Soc., 1981, 103, 7650.

77 G. W. Huffman, P. D. Gesellchen, J. R. Turner, R. B. Rothenberger, H. E. Osborne, F. D. Miller, J. L. Chapman and S. W. Queener, J. Med. Chem., 1992, 35, 1897.

78 A. Daruzzaman, I. J. Clifton, R. M. Adlington, J. E. Baldwin and P. J. Rutledge, ChemBioChem, 2013, 16, 599.

79 S. M. Samson, J. E. Dotzlaf, M. L. Slisz, G. W. Becker, R. M. van Frank, L. E. Veal, W.-K. Yeh, J. R. Miller, S. W. Queener and T. D. Ingolia, Nat. Biotechnol., 1987, 5, 1207.

80 S. Kovacevic, B. J. Weigel, M. B. Tobin, T. D. Ingolia and J. R. Miller, J. Bacteriol., 1989, 171, 754.

81 S. Kovacevic and J. R. Miller, J. Bacteriol., 1991, 173, 398.

82 J. J. R. Coque, F. J. Enguita, R. E. Cardoza, J. F. Martin and P. Liras, Appl. Microbiol. Biotechnol., 1996, 44, 605.

83 B. J. Baker, J. E. Dotzlaf and W.-K. Yeh, J. Biol. Chem., 1991, 266, 5087.

84 J. E. Baldwin, E. P. Abraham, R. M. Adlington, G. A. Bahadur, B. Chakravarti, B. P. Domayne-Hayman, L. D. Field, S. L. Flitsch, G. S. Jayatilake, A. Špakovaskis, H.-H. Ting, N. J. Turner, R. L. White and J. J. Usher, J. Chem. Soc., Chem. Commun., 1984, 1225.

85 Y.-Q. Shen, S. Wolfe and A. L. Demain, J. Antibiot., 1984, 37, 1044.

86 S. Kovacevic, M. B. Tobin and J. R. Miller, J. Bacteriol., 1990, 172, 3952.

87 J. J. R. Coque, J. F. Martin and P. Liras, Mol. Gen. Genet., 1993, 236, 453.

88 S. E. Jensen, D. W. S. Westlake and S. Wolfe, Can. J. Microbiol., 1983, 29, 1526.

89 F. J. Enguita, J. J. R. Coque, P. Liras and J. F. Martin, J. Bacteriol., 1998, 180, 5489.

90 Y. Martínez-Burgoa, R. Álvarez-Álvareza, R. Pérez-Redondob and P. Lirasa, J. Biotechnol., 2014, 186, 21.

91 R. V. Ullán, J. Casqueiro, O. Banûelos, F. J. Fernández, S. Gutiérrez and J. F. Martin, J. Biol. Chem., 2002, 277, 46216.

92 R. V. Ullan, J. Casqueiro, L. Naranjo, I. Vaca and J. F. Martin, Mol. Genet. Genomics, 2004, 272, 562.

93 J. O'Sullivan, R. Aplin, C. Stevens and E. Abraham, Biochem. J., 1979, 179, 47.

94 L. M. Iyer, S. Abhiman, R. F. de Souza and L. Aravind, Nucleic Acids Res., 2010, 38, 5261.

95 L. M. Öster, D. R. Lester, A. Terwisscha van Scheltinga, M. Svenda, M. van Lun, C. Généreux and I. Andersson, J. Mol. Biol., 2006, 358, 546.

96 L. Shao, J. J. Huang, Y. Yu, M. X. Li, T. Pu, S. D. Kan and D. J. Chen, J. Appl. Microbiol., 2014, 117, 1645.

97 C. A. Townsend, A. B. Theis, A. S. Neese, E. B. Barrabee and D. Poland, J. Am. Chem. Soc., 1985, 107, 4760.

98 J. E. Baldwin, R. M. Adlington, N. P. Crouch, N. J. Turner and C. J. Schofield, J. Chem. Soc., Chem. Commun., 1989, 1141.
99 H. Kluender, C. H. Bradley, C. J. Sih, P. Fawcett and E. P. Abraham, J. Am. Chem. Soc., 1973, 95, 6149.

100 N. Neuss, C. H. Nash, J. E. Baldwin, P. A. Lemke and J. B. Grutzner, J. Am. Chem. Soc., 1973, 95, 3797.

101 C. A. Townsend, J. Nat. Prod., 1985, 48, 708.

102 C. P. Pang, R. L. White, E. P. Abraham, D. H. Crout, M. Lutstorf, P. J. Morgan and A. E. Derome, Biochem. J., 1984, 222, 777.

103 J. E. Baldwin, R. M. Adlington, T. W. Kang, E. Lee and C. J. Schofield, Tetrahedron, 1988, 44, 5953.

104 J. E. Baldwin, R. M. Adlington, R. T. Aplin, N. P. Crouch, G. Knight and C. J. Schofield, J. Chem. Soc., Chem. Commun., 1987, 1651.

105 J. E. Baldwin, R. M. Adlington, N. P. Crouch, C. J. Schofield, N. J. Turner and R. T. Aplin, Tetrahedron, 1991, 47, 9881.

106 H. Tarhonskaya, A. Szöllössi, I. K. H. Leung, J. T. Bush, L. Henry, R. Chowdhury, A. Iqbal, T. D. W. Claridge, C. J. Schofield and E. Flashman, Biochemistry, 2014, 53, 2483.

107 I. J. Clifton, M. A. McDonough, D. Ehrismann, N. J. Kershaw, N. Granatino and C. J. Schofield, J. Inorg. Biochem., 2006, 100, 644.

108 J. C. Price, E. W. Barr, B. Tirupati, J. M. Bollinger and C. Krebs, Biochemistry, 2003, 42, 7497.

109 C. Krebs, D. Galonić Fujimori, C. T. Walsh and J. M. Bollinger, Acc. Chem. Res., 2007, 40, 484.

110 J. C. Price, E. W. Barr, T. E. Glass, C. Krebs and J. M. Bollinger, J. Am. Chem. Soc., 2003, 125, 13008.

111 P. J. Riggs-Gelasco, J. C. Price, R. B. Guyer, J. H. Brehm, E. W. Barr, J. M. Bollinger and C. Krebs, J. Am. Chem. Soc., 2004, 126, 8108.

112 L. M. Oester, A. C. T. van Scheltinga, K. Valegard, A. M. Hose, A. Dubus, J. Hajdu and I. Andersson, J. Mol. Biol., 2004, 343, 157.

113 H. J. Lee, M. D. Lloyd, K. Harlos, I. J. Clifton, J. E. Baldwin and C. J. Schofield, J. Mol. Biol., 2001, 308, 937.

114 K. Valegård, A. C. T. van Scheltinga, A. Dubus, G. Ranghino, L. M. Öster, J. Hajdu and I. Andersson, Nat. Struct. Mol. Biol., 2004, 11, 95.

115 M. D. Lloyd, H. J. Lee, K. Harlos, Z. H. Zhang, J. E. Baldwin, C. J. Schofield, J. M. Charnock, C. D. Garner, T. Hara, A. C. T. van Scheltinga, K. Valegard, J. A. C. Viklund, J. Hajdu, I. Andersson, A. Danielsson and R. Bhikhabhai, J. Mol. Biol., 1999, 287, 943.

$116 \mathrm{~J} . \mathrm{Ji}, \mathrm{X}$. Tian, K. Fan and K. Yang, Appl. Microbiol. Biotechnol., 2012, 93, 23951.

117 H. S. Chin, K. S. Goo and T. S. Sim, Appl. Environ. Microbiol., 2004, 70, 607.

118 H. S. Chin and T. S. Sim, Biochem. Biophys. Res. Commun., 2002, 295, 55.

119 K. Fan, B. Lin, Y. Tao and K. Yang, J. Ind. Microbiol. Biotechnol., 2017, 44, 705.

120 K. S. Goo, C.-S. Chua and T.-S. Sim, Appl. Environ. Microbiol., 2008, 74, 1167.

121 K. S. Goo, C.-S. Chua and T.-S. Sim, J. Ind. Microbiol. Biotechnol., 2009, 36, 619.

122 J.-S. Hsu, Y.-B. Yang, C.-H. Deng, C.-L. Wei, S.-H. Liaw and Y.-C. Tsai, Appl. Environ. Microbiol., 2004, 70, 6257. 
123 J. Ji, K. Fan, X. Tian, X. Zhang, Y. Zhang and K. Yang, Appl. Environ. Microbiol., 2012, 78, 7809.

124 H.-J. Lee, C. J. Schofield and M. D. Lloyd, Biochem. Biophys. Res. Commun., 2002, 292, 66.

125 H.-J. Lee, M. D. Lloyd, K. Harlos, I. J. Clifton, J. E. Baldwin and C. J. Schofield, J. Mol. Biol., 2001, 308, 937.

126 M. D. Lloyd, S. J. Lipscomb, K. S. Hewitson, C. M. H. Hensgens, J. E. Baldwin and C. J. Schofield, J. Biol. Chem., 2009, 279, 15420.

127 C.-L. Wei, Y.-B. Yang, W.-C. Wang, W.-C. Liu, J.-S. Hsu and Y.-C. Tsai, Appl. Environ. Microbiol., 2003, 69, 2306.

128 C.-L. Wei, Y.-B. Yang, C.-H. Deng, W.-C. Liu, J.-S. Hsu, Y.-C. Lin, S.-H. Liaw and Y.-C. Tsai, Appl. Environ. Microbiol., 2005, 71, 8673.

129 X.-B. Wu, X.-Y. Tian, J.-J. Ji, W.-B. Wu, K.-Q. Fan and K.-Q. Yang, Biotechnol. Lett., 2011, 33, 805.

130 X.-B. Wu, K.-Q. Fan, Q.-H. Wang and K.-Q. Yang, FEMS Microbiol. Lett., 2005, 246, 103.

131 N. Balakrishnan, S. Ganesan, P. Rajasekaran, L. Rajendran, S. Teddu and M. Durairaaj, Appl. Environ. Microbiol., 2016, 82, 3711.

132 J. W. Janc, L. A. Egan and C. A. Townsend, J. Biol. Chem., 1995, 270, 5399.

133 J. E. Baldwin, M. D. Lloyd, B. Wha-Son, C. J. Schofield, S. W. Elson, K. H. Baggaley and N. H. Nicholson, J. Chem. Soc., Chem. Commun., 1993, 500.

134 S. W. Elson, K. H. Baggaley, J. Gillett, S. Holland, N. H. Nicholson, J. T. Sime and S. R. Woroniecki, J. Chem. Soc., Chem. Commun., 1987, 1736.

135 J. E. Baldwin, R. M. Adlington, J. S. Bryans, A. O. Bringhen, J. B. Coates, N. P. Crouch, M. D. Lloyd, C. J. Schofield, S. W. Elson, K. H. Baggaley, R. Cassels and N. Nicholson, Tetrahedron, 1991, 47, 4089.

136 S. P. Salowe, E. N. Marsh and C. A. Townsend, Biochemistry, 1990, 29, 6499.

137 J. E. Baldwin, R. M. Adlington, J. S. Bryans, A. O. Bringhen, J. B. Coates, N. P. Crouch, M. D. Lloyd, C. J. Schofield, S. W. Elson and K. H. Baggaley, J. Chem. Soc., Chem. Commun., 1990, 617.

138 S. Salowe, W. Krol, D. Iwata-Reuyl and C. Townsend, Biochemistry, 1991, 30, 2281.

139 A. K. MacKenzie, N. J. Kershaw, H. Hernandez, C. V. Robinson, C. J. Schofield and I. Andersson, Biochemistry, 2007, 46, 1523.

140 N. H. Nicholson, K. H. Baggaley, R. Cassels, M. Davison, S. W. Elson, M. Fulston, J. W. Tyler and S. R. Woroniecki, J. Chem. Soc., Chem. Commun., 1994, 1281.

141 J. E. Baldwin, R. M. Adlington, N. P. Crouch, D. J. Drake, Y. Fujishima, S. W. Elson and K. H. Baggaley, J. Chem. Soc., Chem. Commun., 1994, 1133.

142 C. A. Townsend and W. J. Krol, J. Chem. Soc., Chem. Commun., 1988, 1234.

143 B. W. Bycroft, A. Penrose, J. Gillett and S. W. Elson, J. Chem. Soc., Chem. Commun., 1988, 980.

144 L. A. Egan, R. W. Busby, D. Iwata-Reuyl and C. A. Townsend, J. Am. Chem. Soc., 1997, 119, 2348.

145 Z. Zhang, J. Ren, D. K. Stammers, J. E. Baldwin, K. Marios and C. J. Schofield, Nat. Struct. Biol., 2000, 7, 127.
146 J. Zhou, M. Gunsior, B. O. Bachmann, C. A. Townsend and E. I. Solomon, J. Am. Chem. Soc., 1998, 120, 13539.

147 Z. Zhang, J.-S. Ren, K. Harlos, C. H. McKinnon, I. J. Clifton and C. J. Schofield, FEBS Lett., 2002, 517, 7.

148 M. D. Lloyd, K. D. Merritt, V. Lee, T. J. Sewell, B. Wha-Son, J. E. Baldwin, C. J. Schofield, S. W. Elson, K. H. Baggaley and N. H. Nicholson, Tetrahedron, 1999, 55, 10201.

149 A. Basak, S. P. Salowe and C. A. Townsend, J. Am. Chem. Soc., 1990, 112, 1654.

150 T. Borowski, S. de Marothy, E. Broclawik, C. J. Schofield and P. E. M. Siegbahn, Biochemistry, 2007, 46, 3682.

151 A. Endimiani, K. M. Hujer, A. M. Hujer, M. E. Pulse, W. J. Weiss and R. A. Bonomo, Antimicrob. Agents Chemother., 2011, 55, 82.

152 T. Stachyra, M.-C. Pechereau, J.-M. Bruneau, M. Claudon, J.-M. Frere, C. Miossec, K. Coleman and M. T. Black, Antimicrob. Agents Chemother., 2010, 54, 5132.

153 T. Stachyra, P. Levasseur, M.-C. Péchereau, A.-M. Girard, M. Claudon, C. Miossec and M. T. Black, J. Antimicrob. Chemother., 2009, 64, 326.

154 D. E. Ehmann, H. Jahić, P. L. Ross, R. F. Gu, J. Hu, G. Kern, G. K. Walkup and S. L. Fisher, Proc. Natl. Acad. Sci. U. S. A., 2012, 109, 11663.

155 J. E. Baldwin, R. M. Adlington, J. S. Bryans, M. D. Lloyd, T. J. Sewell, C. J. Schofield, K. H. Baggaley and R. Cassels, Tetrahedron, 1997, 53, 7011.

156 M. J. Bodner, R. M. Phelan, M. F. Freeman, R. Li and C. A. Townsend, J. Am. Chem. Soc., 2010, 132, 12.

157 M. F. Freeman, K. A. Moshos, M. J. Bodner, R. Li and C. A. Townsend, Proc. Natl. Acad. Sci. U. S. A., 2008, 105, 11128.

158 R. B. Hamed, L. Henry, J. R. Gomez-Castellanos, J. Mecinović, C. Ducho, J. L. Sorensen, T. D. W. Claridge and C. J. Schofield, J. Am. Chem. Soc., 2012, 134, 471.

159 M. C. Sleeman and C. J. Schofield, J. Biol. Chem., 2004, 279, 6730.

160 R. B. Hamed, J. R. Gomez-Castellanos, A. Thalhammer, D. Harding, C. Ducho, T. D. W. Claridge and C. J. Schofield, Nat. Chem., 2011, 3, 365.

161 L. E. Nunez, C. Mendez, A. F. Brana, G. Blanco and J. A. Salas, Chem. Biol., 2003, 10, 301.

162 R. B. Hamed, E. T. Batchelar, J. Mecinović, T. D. W. Claridge and C. J. Schofield, ChemBioChem, 2009, 10, 246.

163 D. R. Marous, E. P. Lloyd, A. R. Buller, K. A. Moshos, T. L. Grove, A. J. Blaszczyk, S. J. Booker and C. A. Townsend, Proc. Natl. Acad. Sci. U. S. A., 2015, 112, 10354.

164 R. Li, E. P. Lloyd, K. A. Moshos and C. A. Townsend, ChemBioChem, 2014, 15, 320.

165 J. Shoji, H. Hinoo, R. Sakazaki, N. Tsuji, K. Nagashima, K. Matsumoto, Y. Takahashi, S. Kozuki, T. Hattori, E. Kondo and K. Tanaka, J. Antibiot., 1982, 35, 15.

166 N. Tsuji, K. Nagashima, M. Kobayashi, J. Shoji, T. Kato, Y. Terui, H. Nakai and M. Shiro, J. Antibiot., 1982, 35, 24.

167 S. J. McGowan, M. Sebaihia, L. E. Porter, G. S. A. B. Stewart, P. Williams, B. W. Bycroft and G. P. C. Salmond, Mol. Microbiol., 1996, 22, 415. 
168 S. J. McGowan, M. Sebaihia, S. O'Leary, K. R. Hardie, P. Williams, G. S. A. B. Stewart, B. W. Bycroft and G. P. C. Salmond, Mol. Microbiol., 1997, 26, 545.

169 R. F. Li, A. Stapon, J. T. Blanchfield and C. A. Townsend, J. Am. Chem. Soc., 2000, 122, 9296.

170 A. Stapon, R. Li and C. A. Townsend, J. Am. Chem. Soc., 2003, 125, 15746.

171 M. C. Sleeman, P. Smith, B. Kellam, S. R. Chhabra, B. W. Bycroft and C. J. Schofield, ChemBioChem, 2004, 5, 879.

172 I. J. Clifton, L. X. Doan, M. C. Sleeman, M. Topf, H. Suzuki, R. C. Wilmouth and C. J. Schofield, J. Biol. Chem., 2003, 278, 20843.

173 W.-C. Chang, Y. Guo, C. Wang, S. E. Butch, A. C. Rosenzweig, A. K. Boal, C. Krebs and J. M. Bollinger Jr, Science, 2014, 242, 1140.

174 A. Stapon, R. Li and C. A. Townsend, J. Am. Chem. Soc., 2003, 125, 8486.

175 M. Topf, G. M. Sandala, D. M. Smith, C. J. Schofield, C. J. Easton and L. Radom, J. Am. Chem. Soc., 2004, 126, 9932.

176 T. Borowski, E. Broclawik, C. J. Schofield and P. E. M. Siegbahn, J. Comput. Chem., 2006, 27, 74.

177 R. M. Phelan and C. A. Townsend, J. Am. Chem. Soc., 2013, 135, 7496.

178 J. O'Sullivan, A. M. Gillum, C. A. Aklonis, M. L. Souser and R. B. Sykes, Antimicrob. Agents Chemother., 1982, 21, 558.

179 J. O'Sullivan, M. L. Souser, C. C. Kao and C. A. Aklonis, Antimicrob. Agents Chemother., 1983, 23, 598.
180 M. E. Horsman, D. R. Marous, R. Li, R. A. Oliver, B. Byun, S. J. Emrich, B. Boggess, C. A. Townsend and S. Mobashery, ACS Chem. Biol., 2017, 12, 2552.

181 N. M. Gaudelli, D. H. Long and C. A. Townsend, Nature, 2015, 520, 383.

182 R. Li, R. A. Oliver and C. A. Townsend, Cell Chem. Biol., 2017, 24, 24.

183 J. M. Davidsen, D. M. Bartley and C. A. Townsend, J. Am. Chem. Soc., 2013, 135, 1749.

184 M. Asai, K. Haibara, M. Muroi, K. Kintaka and T. Kishi, J. Antibiot., 1981, 34, 621.

185 W. Stephen Faraci and R. F. Pratt, Biochemistry, 1986, 25, 2934.

186 T. G. Kinscherf and D. K. Willis, J. Antibiot., 2005, 58, 817.

187 B. Lin, K. Fan, J. Zhao, J. Ji, L. Wu, K. Yang and Y. Tao, Proc. Natl. Acad. Sci. U. S. A., 2015, 112, 9855.

188 A. R. Awan, B. A. Blount, D. J. Bell, W. M. Shaw, J. C. H. Ho, R. M. McKiernan and T. Ellis, Nat. Commun., 2017, 8, DOI: 10.1038/ncomms15202.

189 T.-L. Yeh, T. M. Leissing, M. I. Abboud, C. C. Thinnes, O. Atasoylu, J. P. Holt-Martyn, D. Zhang, A. Tumber, K. Lippl, C. T. Lohans, I. K. H. Leung, H. Morcrette, I. J. Clifton, T. D. W. Claridge, A. Kawamura, E. Flashman, X. Lu, P. J. Ratcliffe, R. Chowdhury, C. W. Pugh and C. J. Schofield, Chem. Sci., 2017, 8, 7651. 